\title{
What would have happened to the ozone layer if chlorofluorocarbons (CFCs) had not been regulated?
}

\author{
P. A. Newman ${ }^{1}$, L. D. Oman ${ }^{2}$, A. R. Douglass ${ }^{1}$, E. L. Fleming ${ }^{3}$, S. M. Frith ${ }^{3}$, M. M. Hurwitz ${ }^{4}$, S. R. Kawa ${ }^{1}$, \\ C. H. Jackman ${ }^{1}$, N. A. Krotkov ${ }^{5}$, E. R. Nash $^{3}$, J. E. Nielsen ${ }^{3}$, S. Pawson ${ }^{1}$, R. S. Stolarski ${ }^{1}$, and G. J. M. Velders ${ }^{6}$ \\ ${ }^{1}$ NASA Goddard Space Flight Center, Greenbelt, Maryland, USA \\ ${ }^{2}$ Johns Hopkins University, Baltimore, Maryland, USA \\ ${ }^{3}$ Science Systems and Applications, Inc., Lanham, Maryland, USA \\ ${ }^{4}$ NASA Postdoctoral Program, NASA Goddard Space Flight Center, Greenbelt, Maryland, USA \\ ${ }^{5}$ Goddard Earth Sciences and Technology Center, University of Maryland, Baltimore County, Baltimore, Maryland, USA \\ ${ }^{6}$ Netherlands Environmental Assessment Agency, Bilthoven, The Netherlands
}

Received: 22 September 2008 - Published in Atmos. Chem. Phys. Discuss.: 10 December 2008

Revised: 17 March 2009 - Accepted: 18 March 2009 - Published: 23 March 2009

\begin{abstract}
Ozone depletion by chlorofluorocarbons (CFCs) was first proposed by Molina and Rowland in their 1974 Nature paper. Since that time, the scientific connection between ozone losses and CFCs and other ozone depleting substances (ODSs) has been firmly established with laboratory measurements, atmospheric observations, and modeling studies. This science research led to the implementation of international agreements that largely stopped the production of ODSs. In this study we use a fully-coupled radiationchemical-dynamical model to simulate a future world where ODSs were never regulated and ODS production grew at an annual rate of $3 \%$. In this "world avoided" simulation, $17 \%$ of the globally-averaged column ozone is destroyed by 2020, and 67\% is destroyed by 2065 in comparison to 1980 . Large ozone depletions in the polar region become yearround rather than just seasonal as is currently observed in the Antarctic ozone hole. Very large temperature decreases are observed in response to circulation changes and decreased shortwave radiation absorption by ozone. Ozone levels in the tropical lower stratosphere remain constant until about 2053 and then collapse to near zero by 2058 as a result of heterogeneous chemical processes (as currently observed in the Antarctic ozone hole). The tropical cooling that triggers the ozone collapse is caused by an increase of the tropical upwelling. In response to ozone changes, ultraviolet radiation increases, more than doubling the erythemal radiation in the northern summer midlatitudes by 2060 .
\end{abstract}

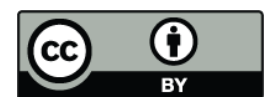

Correspondence to: P. A. Newman (paul.a.newman@nasa.gov)

\section{Introduction}

Molina and Rowland (1974) were the first to propose that ozone could be depleted by the release of chlorofluorocarbons (CFCs) to the atmosphere. The chemical breakdown of CFCs and other ozone depleting substances (ODSs) in the stratosphere releases chlorine $(\mathrm{Cl})$ and bromine $(\mathrm{Br})$ atoms that destroy ozone molecules in catalytic cycles. Ozone depletion would result in an increase of biologically harmful solar ultraviolet (UV) radiation. Early predictions of ozone loss were 15-18\% if CFCs added 5.5-7.0 ppbv of chlorine to the stratosphere (Hudson and Reed, 1979). Continued scientific research led to the writing of a series of reports that culminated in the first World Meteorological Organization (WMO)/United Nations Environment Program scientific assessment of ozone depletion (WMO, 1985). This assessment provided the scientific consensus that CFCs and halons posed a serious threat to the ozone layer. In response, the landmark Montreal Protocol agreement was negotiated in 1987 (Sarma and Bankobeza, 2000). This agreement regulated the production of chlorofluorocarbons and other ODSs. Since 1987, 193 nations have signed the Montreal Protocol. Five amendments to the Montreal Protocol have now led to the cessation of the major portions of ODS production around the world. The cumulative levels of chlorine and bromine from the ODSs are now decreasing in both the troposphere (Montzka et al., 1996) and the stratosphere (Anderson et al., 2000; Froidevaux et al., 2006). The work of Molina and Rowland (1974) led to a major reorganization and redirection of chemical production to substitute compounds, to changes in technologies that traditionally used CFCs, and to the first international agreement on regulation of chemical pollutants.

Published by Copernicus Publications on behalf of the European Geosciences Union. 
The regulation of ODSs was based upon the ozone assessments that presented the consensus of the science community. The regulation presupposed that a lack of action would lead to severe ozone depletion with consequent severe increases of solar UV radiation levels at the Earth's surface. Because of the successful regulation of ODSs, ozone science has now entered into the accountability phase. There are two relevant questions in this phase. First, are ODS levels decreasing and ozone increasing as expected because of the Montreal Protocol regulations? Second, what would have happened to the atmosphere if no actions had been taken? That is to say, what kind of world was avoided? It is this latter question that is the focus of the present study.

Two studies have modeled the impact of high levels of CFCs on ozone. First, Prather et al. (1996) modeled the ozone response to continued growth of the ODSs without the Montreal Protocol and its amendments. They hypothesized that ODSs continued to grow at "business-as-usual" growth rates from 1974 into the early 21 st century. Such ODS growth could have resulted from a lack of understanding of ozone depletion, a failure to regulate ODS production, and further development of technologies that used CFCs. In their study, ODSs were allowed to grow by approximately $5-7 \%$ per year, resulting in a total stratospheric chlorine $\left(\mathrm{Cl}_{\mathrm{y}}\right)$ level of about 9 ppbv by 2002. They used a two-dimensional (2$\mathrm{D}$, or latitude-altitude) model with projected CFC and halon levels to calculate a globally-averaged total ozone depletion of $10 \%$ by 1999 . Second, Morgenstern et al. (2008) used a three-dimensional (3-D, or longitude-latitude-altitude) coupled chemistry-climate model (CCM) to simulate the impact of $9 \mathrm{ppbv}$ on the stratosphere in a timeslice or fixed time mode (equivalent to levels of $\mathrm{Cl}_{\mathrm{y}}$ that they estimated would have been reached in about 2030). In their simulation they found peak ozone depletions ( $>35 \%)$ in the upper stratosphere, with additional ozone depletion in both polar regions $(>20 \%)$.

In addition to the ozone studies, Velders et al. (2007) have recently investigated the impact of unrestrained growth of CFCs on climate. They pointed out that because CFCs and other ODSs are also greenhouse gases, the ODSs would have added an additional $0.8-1.6 \mathrm{~W} \mathrm{~m}^{-2}$ of radiative forcing by 2010 if the ODSs had continued to grow at 3-7\% per year after 1974. Hence, the implementation of the Montreal Protocol has limited both ozone depletion and climate change.

Prather et al. (1996) were limited by using a fixed transport 2-D model (Jackman et al., 1996) to produce their estimates of ozone loss. Since this version of the 2-D model did not include the feedback among radiative, dynamical, and chemical processes, the model simulations were terminated when total ozone depletion reached $10 \%$. Such significant computed total ozone depletion was assumed to cause large stratospheric changes, both radiatively and dynamically. Models of the stratosphere have greatly improved over the last decade. 2-D models parameterize longitudinal variations, hence 3-D models better account for longitudinal vari- ations and more realistically represent the polar latitude dynamics. State-of-the-art models now have complex feedback among the chemical, radiative, and dynamical processes.

Here we employ the Goddard Earth Observing System (GEOS) chemistry-climate model to explore the ozone distributions that might have been without ODS regulations (a "world avoided"), updating and extending the results of Prather et al. (1996) up to 2065. Because ozone is a radiatively active gas in both the ultraviolet and the infrared, the destruction of ozone alters the temperature and the wind distributions, which then affects the transport of ozone and other gases. Further, as temperatures change, ozone loss rates change, producing a feedback that further alters the ozone distribution. Hence, a proper simulation of the "world avoided" requires a CCM with interactive radiation, chemistry, and dynamics.

This "world avoided" estimate of ozone depletion is performed for a few basic reasons. First, scientists predicted massive ozone losses, actions were taken, and these losses have not occurred. Hence, do the state-of-the-art models actually predict the large losses that were hypothesized in the 1980s? Second, such model estimates give an indication of the unforeseen impacts of large ozone losses on the chemistry and climate of the stratosphere. Such extreme simulations are useful for evaluating theoretical expectations of dynamics and chemistry (e.g., how does the tropopause change if the ozone layer is destroyed?). Third, a transient simulation provides an ensemble of total chlorine and bromine values and their associated ozone losses, from small chlorine values in the 1960s to high chlorine values in the 2060s. Because we cannot actually predict how large CFC and other ODS concentrations might have become, this simulation provides a large range of CFC levels from which to choose. Finally, and most importantly, this type of estimate provides a quantitative baseline for assessing the impact of international agreements on ozone, UV radiation impacts, and climate change. The acknowledged success of the Montreal Protocol in the present is best measured against what might have been without that agreement.

The scope of this study is limited to describing the very large ozone losses and the subsequent rise of ultraviolet (UV) levels. We only include highlights of the radiative, chemical, and dynamical effects in the stratosphere. The large CFC perturbations used here lead to large chemical ozone losses and large dynamical changes that lead to large ozone changes. In this study, we have not attempted to separate these chemical and dynamical effects, but refer to them together as ozone losses. There are eight sections including the introduction. Section 2 describes the experiment with subsections on the model and the details of the simulations. Section 3 describes the evolution of halogens in the model experiments. Section 4 describes the evolution and distributions of ozone. Sections 5 and 6 discuss some important aspects of the chemistry and dynamics, respectively. Section 7 provides estimates of surface ultraviolet levels. The 
final section provides a summary and discussion of some important aspects of this "world avoided" scenario.

\section{Experiment}

The model simulations use the GEOSCCM, which is described in detail by Pawson et al. (2008).

\subsection{Model description}

The model has a horizontal resolution of $2^{\circ}$ latitude by $2.5^{\circ}$ longitude with 55 vertical levels up to $0.01 \mathrm{hPa}(80 \mathrm{~km})$. The dynamical time step is $7.5 \mathrm{~min}$. The model uses a flux-form semi-Lagrangian dynamical core (Lin, 2004) and a mountain-forced gravity-wave drag scheme with a wave forcing for non-zero phase speeds (Garcia and Boville, 1994; Kiehl et al., 1998). The sub-grid moisture physics and radiation are adapted from Kiehl et al. (1998), as described by Bosilovich et al. (2005). The model does not include either an internally generated or a forced quasi-biennial oscillation. The photochemistry code is based on the family approach, as described by Douglass and Kawa (1999) and uses the chemical kinetics from Sander et al. (2003). Tropospheric ozone is relaxed to a climatology (Logan, 1999) with a 5-day time scale. A total of 35 trace gases are transported in the model. Gases with surface sources are specified as mixing ratios in the lowest model layer (e.g., "greenhouse gases" such as carbon dioxide $\left(\mathrm{CO}_{2}\right)$ and "ozone-depleting gases" such as CFC-11. The coupling between the chemical and physical state of the atmosphere occurs directly through the GCM's radiation code. The model-simulated water vapor $\left(\mathrm{H}_{2} \mathrm{O}\right), \mathrm{CO}_{2}$, ozone $\left(\mathrm{O}_{3}\right)$, methane $\left(\mathrm{CH}_{4}\right)$, nitrous oxide $\left(\mathrm{N}_{2} \mathrm{O}\right), \mathrm{CFC}-11, \mathrm{CFC}-12$, and HCFC-22 are used in the radiation computations. The same A1b Intergovernmental Panel on Climate Change (IPCC) greenhouse gas scenario (Table II.2.1, ISAM model reference, and Tables II.2.2 and II.2.3 from Houghton et al., 2001) is used for $\mathrm{CO}_{2}, \mathrm{CH}_{4}$, and $\mathrm{N}_{2} \mathrm{O}$ in all of our simulations.

Processes involving polar stratospheric clouds (PSCs) use an update of the parameterization described by Considine et al. (2000). In this approach PSC particles composed of nitric acid trihydrate (NAT) or water ice form instantaneously when the ambient mixing ratios of nitric acid $\left(\mathrm{HNO}_{3}\right)$ or $\mathrm{H}_{2} \mathrm{O}$ are above the respective saturation mixing ratio, which is a function of temperature and pressure $\left(\right.$ and $\mathrm{H}_{2} \mathrm{O}$ mixing ratio for NAT). No supersaturation is required for PSC formation in this simulation. PSC reactive surface area is calculated from the amount of condensed mass assuming a prescribed particle number concentration for either ice or NAT. Particle sedimentation follows from a log-normal size distribution. In the simulation of the "world avoided", both NAT and ice sedimentation directly redistribute $\mathrm{HNO}_{3}$ and $\mathrm{H}_{2} \mathrm{O}$ vertically between grid boxes; no separate dehydration parameter is needed as in Considine et al. (2000). Heterogeneous reaction efficiencies (sticking coefficient) are calculated for the appropriate surface type: liquid sulfate, NAT, or ice, as in Kawa et al. (1997) updated to Sander et al. (2003). The sulfate aerosol surface area is based upon Stratospheric Aerosol and Gas Experiment (SAGE) observations, and is specified as a climatological zonal mean varying as a function of month, altitude, and latitude for non-volcanically influenced periods (Chipperfield et al., 2003).

GEOSCCM has been compared to observations and other models and does very well in reproducing past climate and key transport processes (Eyring et al., 2006; Stolarski et al., 2006; Pawson et al., 2008; Oman et al., 2009). Pawson et al. (2008) showed good agreement between the ozone simulations and observations, but noted a slightly high total ozone bias and a too cold and long-lived Antarctic vortex. $\mathrm{Cl}_{\mathrm{y}}$ has been estimated from observations by Lary et al. (2007), and shows good agreement with the GEOSCCM values (Eyring et al., 2007). In addition, hydrochloric acid ( $\mathrm{HCl})$ from GEOSCCM has also been compared to observations and shows excellent agreement (Eyring et al., 2006). Predictions from the GEOSCCM have been compared to other model predictions (Eyring et al., 2007), showing good general agreement with other CCMs. These comparisons of both ozone and chlorine observations give us high confidence in the GEOSCCM projections.

\subsection{Model simulations}

There are four simulations used in this study: a "reference past", a "reference future", a "fixed chlorine" (with chlorine levels fixed at the 1960 level), and the "WORLD AVOIDED". Table 1 summarizes the four simulations. Figures in this study that compare the simulations use color to distinguish between them, using blue for the reference past, red for the reference future, green for the fixed chlorine, and black for the WORLD AVOIDED. The first three simulations have been described by Pawson et al. (2008) and Oman et al. (2009). The reference past and reference future simulations have also been described by Eyring et al. (2006) and Eyring et al. (2007), respectively.

The reference past simulation is an attempt to simulate the past observations of the atmosphere. Hence this simulation is forced by the observed ODSs at the surface (Montzka et al., 2003), and uses the observed sea surface temperatures (SSTs) and ice distribution (Rayner et al., 2003). The reference future is an attempt to simulate the future using our best guesses for future ODSs (Montzka et al., 2003) and SSTs. There are two reference future simulations shown herein. All of the reference future plots versus time use the same simulation shown by Eyring et al. (2007) that was forced with the HadGEM1 SSTs. All of the zonal mean difference plots use a reference future simulation that is forced with the National Center for Atmospheric Research (NCAR) Community Climate System Model version 3 (CCSM3) SSTs (Collins et al., 2006). This second reference future simulation (B in Table 1) 
Table 1. GEOSCCM simulations description

\begin{tabular}{|c|c|c|c|}
\hline Simulation & Year range & ODS scenario & Prescribed SSTs \\
\hline Reference past & 1950-2004 & $A b^{\mathrm{a}}$ & Observations: HadISST $1^{\text {b }}$ \\
\hline Reference future & $\begin{array}{l}1996-2099 \\
2000-2099\end{array}$ & $\mathrm{Ab}^{\mathrm{a}}$ & $\begin{array}{l}\text { A: HadGEM } 1^{\text {c }} \\
\text { B: NCAR CCSM3 SRESA1B }\end{array}$ \\
\hline Fixed chlorine & $1960-2100$ & $\mathrm{Ab}^{\mathrm{a}}$, fixed to 1960 & $\begin{array}{l}\text { 1960-2000: Observations: HadISST1 }{ }^{\text {b }} \\
\text { 2001-2100: NCAR CCSM3 PCMDI }\end{array}$ \\
\hline WORLD AVOIDED & 1974-2065 & $+3 \%$ per year & $\begin{array}{l}\text { 1974-2049: NCAR CCSM2 SRESA1B } \\
\text { 2050-2065: NCAR CCSM3 SRESA1B }\end{array}$ \\
\hline
\end{tabular}

\footnotetext{
${ }^{a}$ Montzka et al. (2003)

b Rayner et al. (2003)

c Johns et al. (2006)
}

is used because the SSTs are consistent with the WORLD AVOIDED simulation in the period from 2050 to 2065 . The differences between these two reference future simulations are quite small in the stratosphere.

The WORLD AVOIDED simulation extends from 1974 through 2065. This simulation is driven by one of the mixing ratio scenarios established in Velders et al. (2007). The ODS estimates are based upon a scenario (their MR74) wherein production of the CFC-11, CFC-12, CFC-113, CFC-114, CFC-115, carbon tetrachloride, methyl chloroform, HCFC22, HCFC-142b, halon 1301, and methyl bromide increases annually at 3\% per year beginning in 1974. In this scenario, there was no early warning of the danger of CFCs as actually occurred because of Molina and Rowland (1974). The 3\% per year production growth is lower than the observed growth of $12-17 \%$ in CFC production in the period up to 1974 . The surface total chlorine reaches a level of $9 \mathrm{ppbv}$ in 2012. In contrast, the CFC growth used in Prather et al. (1996) was approximately $7 \%$ and $\mathrm{Cl}_{\mathrm{y}}$ reached a level of $9 \mathrm{ppbv}$ in about 2002. Morgenstern et al. (2008) compared two fixed $\mathrm{Cl}_{\mathrm{y}}$ levels of $3.5 \mathrm{ppbv}$ and $9 \mathrm{ppbv}$ in their timeslice simulation. In our WORLD AVOIDED simulation, the upper stratospheric $\mathrm{Cl}_{\mathrm{y}}$ reaches 9 ppbv in about 2019 .

Reliable estimates of surface temperature changes can only be made using coupled atmosphere-ocean general circulation models (AOGCMs) (Houghton et al., 1990). In our CCM we attempt to overcome this problem by using SSTs that are consistent with increasing greenhouse gases. The SSTs and sea ice used in the WORLD AVOIDED simulation are derived from two integrations of the NCAR Community Climate System Model, from the version 2 (CCSM2) for 1974-2049 and from the CCSM3 for 2050-2065. The latter is from an IPCC AR4 integration, but both are consistent with the IPCC A1b scenario growth of greenhouse gases. A limitation of this prescribed SST approach is that it is inconsistent with the growth of the ODSs in our WORLD AVOIDED simulation. Since ODSs are also greenhouse gases, they introduce a direct radiative forcing in the atmosphere (less so in the stratosphere since CFCs are destroyed there). Ozone is also a greenhouse gas, so stratospheric ozone changes also provide a radiative forcing of the troposphere. The prescribed SST used herein acts as a thermal sink, constraining the troposphere to evolve in parallel with $\mathrm{A} 1 \mathrm{~b}$ greenhouse gas growth rather than with the additional radiative forcing from the higher levels of CFCs. Assuming a climate sensitivity parameter of $0.5 \mathrm{~K}\left(\mathrm{~W} \mathrm{~m}^{-2}\right)^{-1}$ (Ramanathan et al., 1985), the additional CFCs would contribute a surface warming of very roughly $0.25 \mathrm{~K}$ by 2010 following the Velders et al. (2007) estimates of the CFC induced radiative forcing. Hence, the WORLD AVOIDED troposphere and oceans are too cold compared with what would develop for the same scenario using an AOGCM. Furthermore, the extreme UV levels simulated here would also impact tropospheric chemistry, tropospheric ozone radiative forcing, and biogeochemical processes. The GEOSCCM model is a stratosphere-only chemistry model that uses a climatological distribution of ozone in the troposphere. While tropospheric reductions of ozone are evident in the model's ozone field, these reductions are solely a result of the advection of low ozone from the stratosphere.

We also simulated the WORLD AVOIDED using a coupled chemistry 2-D model with the Velders et al. (2007) MR74 scenario. This 2-D model is an updated version of that used by Rosenfield et al. (2002). This is also an improvement over the 2-D model of Prather et al. (1996) that utilized prescribed transport fields that did not interact with the evolution of the chemical fields. Our newer model has fully interactive chemistry, radiation, and dynamics, and includes a parameterization of eddy effects that interact with the mean circulation (Garcia, 1991). While the dynamics, chemistry, and physics of the GEOSCCM and the 2-D model are very distinct, the newer 2-D model results are in good quantitative agreement with the results herein from the GEOSCCM WORLD AVOIDED simulation. 


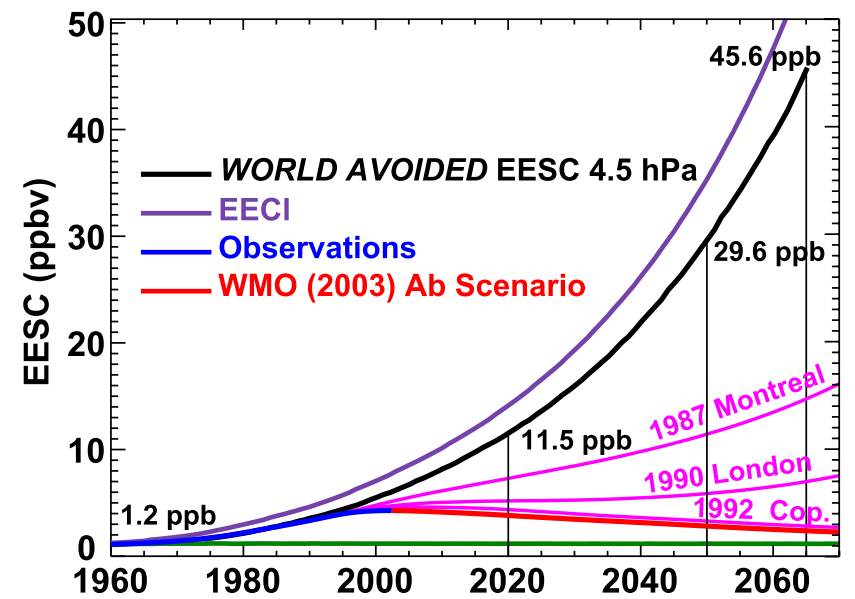

Fig. 1. EESC versus year for the WORLD AVOIDED as globallyaveraged from the model's inorganic chlorine and bromine at $4.5 \mathrm{hPa}$ (thick black line). The magenta lines show scenarios from the Montreal Protocol, the London Amendments, and the Copenhagen Amendments. The red line indicates the estimate of ODS evolution in the $\mathrm{Ab}$ scenario and the blue line indicates observationally based EESC (Montzka et al., 2003). The green line shows the fixed level of 1960 chlorine (1.2 ppbv). EECl for the WORLD $A V O I D E D$ is shown as the dark purple line.

\section{Atmospheric halogens}

In this WORLD AVOIDED simulation, stratospheric ODS levels increase rapidly after 2000. Figure 1 shows the equivalent effective chlorine (EECl) from Velders et al. (2007) (purple line) that is used as the surface mixing ratio boundary condition in the WORLD AVOIDED simulation. This $\mathrm{EECl}$ is estimated by totaling all of the inorganic chlorine and bromine separately and then adding them with the inorganic bromine multiplied by a factor of 60 to account for the greater efficiency of bromine for ozone destruction.

The effective equivalent stratospheric chlorine (EESC) (thick black line) is calculated in Fig. 1 from the model output by summing the globally-averaged $\mathrm{Cl}_{\mathrm{y}}$ and total stratospheric bromine $\left(\mathrm{Br}_{\mathrm{y}}\right)$ at $4.5 \mathrm{hPa}$ with a $\mathrm{Br}_{\mathrm{y}}$ scaling factor of 60. The WORLD AVOIDED EESC is somewhat uncertain because the scaling factor of 60 used for the estimate of the $\mathrm{Br}_{\mathrm{y}}$ contribution will change at very high concentrations of $\mathrm{Cl}_{\mathrm{y}}$ (Danilin et al., 1996). We also theoretically estimate EESC following Newman et al. (2007), using the surface mixing ratio estimates and fractional release rates for each species, and an age spectrum with a 6-year mean age. This theoretical EESC (not shown here) overlaps the model EESC, giving us good confidence in these model estimates. In addition, Froidevaux et al. (2006) estimated total chlorine from Microwave Limb Sounder $\mathrm{HCl}$ observations in the upper stratosphere as approximately $3.6 \mathrm{ppbv}$ in 2006 with a slow decrease of about $0.8 \%$ per year. The reference fu-

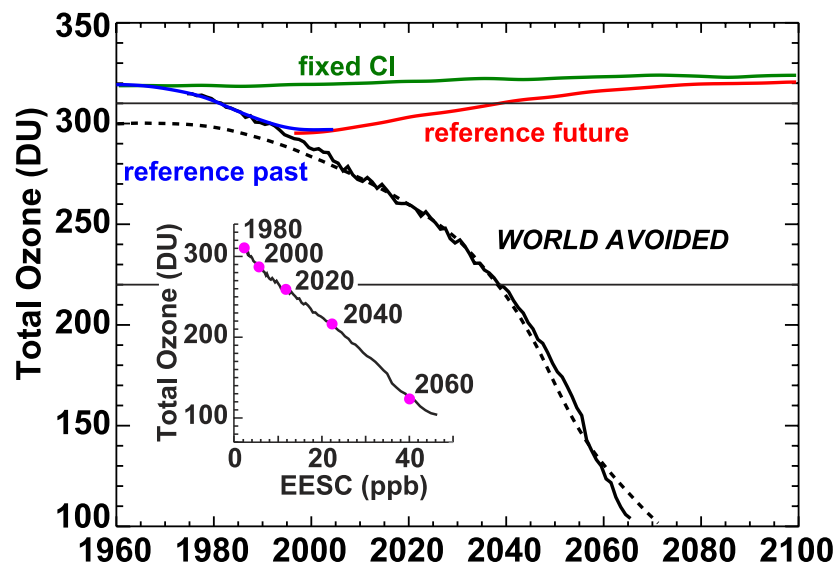

Fig. 2. Annual average global ozone for the WORLD AVOIDED (solid black), reference future (red), fixed chlorine (green), and reference past (blue) simulations. The curves are smoothed with a Gaussian filter with a half-amplitude response of 20 years, except for the WORLD AVOIDED, which is unsmoothed. The dashed line shows the 2-D coupled model simulation of the "world avoided". The thin horizontal lines indicate the 220-DU level (the level usually indicating the areal extent of the Antarctic ozone hole) and the 310-DU level (the 1980 global value). The inset shows the WORLD AVOIDED total ozone plotted against global annuallyaveraged EESC at $4.5 \mathrm{hPa}$ from Fig. 1.

ture simulation has a peak in total chlorine of $3.4 \mathrm{ppbv}$ with a decrease that matches the observed $0.8 \%$ per year, again giving us good confidence in our ability to simulate chlorine levels. The time lag between the model EESC and the $\mathrm{EECl}$ is accounted for by the transit time from the Earth's surface to the upper stratosphere $(\approx 4-6$ years). The EESC theoretical estimates (again following Newman et al., 2007) are shown for the Montreal Protocol, the London Amendments, the Copenhagen Amendments, observations, and scenario Ab (Montzka et al., 2003). The current A1 scenario (Daniel et al., 2007) is not shown here, but nearly overlaps the Ab scenario in Fig. 1.

The natural level of EESC is estimated to be approximately 1.2 ppbv (noted at the left in Fig. 1). In the Ab scenario, the EESC reached a peak level of about $4.3 \mathrm{ppbv}$ in approximately 2002. The WORLD AVOIDED scenario has EESC increasing to $11.5 \mathrm{ppbv}$ by 2020 and $29.6 \mathrm{ppbv}$ by 2050. In contrast, scenario Ab has EESC falling to $3.8 \mathrm{ppbv}$ in 2020 and 2.8 ppbv by 2050 .

\section{Ozone}

Figure 2 displays the global annual average total ozone levels from the four simulations. Total ozone falls from about $315 \mathrm{DU}$ in 1974 to about $110 \mathrm{DU}$ in 2065 in the WORLD AVOIDED simulation. Approximately $27 \mathrm{DU}$ of this annually-averaged total ozone is in the troposphere over 
the entire period. A value of less than $220 \mathrm{DU}$ is nominally used to estimate the location and areal extent of the Antarctic ozone hole. The global annual average passes $220 \mathrm{DU}$ shortly before 2040 .

Figure 2 also shows the WORLD AVOIDED simulation (with the same ODS scenario) using the coupled chemistry 2-D model (dashed line). The 2-D model shows less ozone prior to 2000. However, in spite of the large differences in these model implementations (e.g., 2-D vs. 3-D, chemical schemes, dynamical parameterizations, etc.), the two models show very good agreement after 2000 , which provides confidence in the magnitudes of the ozone losses.

This good agreement between the 2-D and 3-D models is not surprising in light of previous studies, which showed that the zonally-averaged stratospheric ozone and tracer fields simulated by 3-D models were well represented by selfconsistent 2-D model simulations on time scales of 30 days or longer (e.g., Plumb and Mahlman, 1987; Yudin et al., 2000). Also, our previous work has shown that a 2-D model framework can successfully reproduce many of the transportsensitive features seen in a variety of stratospheric ozone and tracer observations (Fleming et al., 1999). The good 2-D/3$\mathrm{D}$ model agreement also illustrates that the propagation and breakdown of planetary waves in the stratosphere, and the related interactions with the zonal mean flow, are well represented by the linearized planetary wave parameterization used in our 2-D model (Garcia, 1991), even in this highly perturbed WORLD AVOIDED scenario.

The sensitivity of total ozone to chlorine is roughly linear over the time period simulated. The inset to Fig. 2 shows the total ozone plotted against the model EESC. The ozone level is linearly anti-correlated with the EESC level. While the temporal tendency in Fig. 2 shows an accelerating decline (i.e., the change between 2040 and 2060 is greater than the change between 2020 and 2040), this is a result of the accelerating increase of ODSs, rather than a greater sensitivity to ODSs.

Substantial reduction of ozone occurs at all latitudes in the WORLD AVOIDED simulation. Figure 3 shows annuallyaveraged total ozone for a series of years from all four simulations. The total ozone in 1970 is represented by the fixed chlorine and reference past simulations (both have comparable EESC levels in 1970, see Fig. 1). These simulations are in reasonable agreement with observations (see Pawson et al., 2008) with a global total ozone average of about $310 \mathrm{DU}$. The reference future and WORLD AVOIDED simulations show substantial ozone losses by 2000 as ODSs increase. This loss trend continues as ODSs increase, such that global total ozone has fallen to a value of about $120 \mathrm{DU}$ by 2065 in the WORLD AVOIDED simulation. The midlatitude maximum in both hemispheres has virtually disappeared by 2065 , and annually-averaged polar values have dropped below 100 DU. In addition, this midlatitude maximum slowly shifts equatorward in both hemispheres. A substantial portion of the remaining total column is found in the troposphere

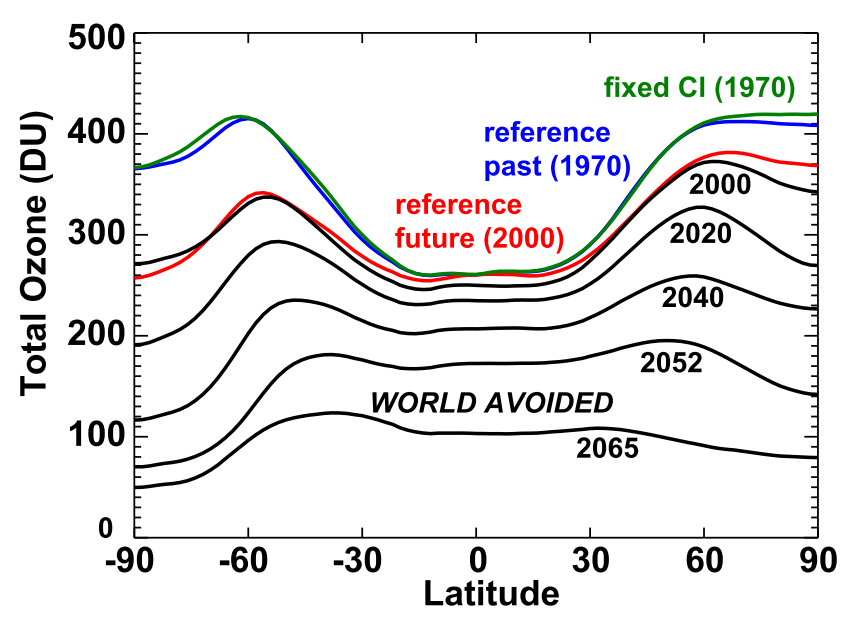

Fig. 3. Annually-averaged total ozone versus latitude for various years from the WORLD AVOIDED (black), reference future (red), fixed chlorine (green), and reference past (blue) simulations. The pole-to-pole area-weighted averages are shown in Fig. 2.

(approximately 20 DU in the Antarctic, 24 DU in the Arctic, and $20 \mathrm{DU}$ in the tropics, with a global average tropospheric column of $27 \mathrm{DU})$.

In the WORLD AVOIDED simulations polar total ozone also shows severe losses. Over the Arctic (Fig. 4a), ozone decreases from values near $500 \mathrm{DU}$ in the 1960-1980 period to less than 100 DU by 2065 (an $80 \%$ depletion over approximately an 80-year time span). Approximately $24 \mathrm{DU}$ of this remaining Arctic column is in the troposphere. The inset images show the April monthly averages for 1980, 2020, and 2040. In 1980, the large column amounts cover the Arctic region (values $>500$ DU). By 2020, a distinct "ozone hole" minimum has developed over the Arctic with a low value near the pole that is less than 200 DU. By 2060 values of less than $100 \mathrm{DU}$ are found over the Arctic. The positive gradient of ozone between the midlatitudes and the pole seen in 1980 has disappeared by 2060 .

Over Antarctica (Fig. 4b), the October average drops below 100 DU in approximately 2025 and continues to slowly decrease to about $50 \mathrm{DU}$ by 2060 . Of this $50 \mathrm{DU}$, approximately $20 \mathrm{DU}$ is found in the troposphere. The inset images show the October averages for 1980, 2020, and 2060. In 1980, a distinct ozone low is seen over Antarctica. By 2040, this low has considerably deepened, and by 2060 extremely low values are observed across Antarctica and into midlatitudes. These October images also show the very large depletions of ozone in the midlatitude collar region.

Antarctic ozone, at the profile peak $(\approx 50 \mathrm{hPa})$, reaches $100 \%$ loss by 2000 (saturation), as observed in ozonesondes (Solomon et al., 2005). This saturation occurs because of the colder Antarctic temperatures and thereby greater coverage of PSCs and cold sulfate aerosols. The heterogeneous reactions on the surfaces of these PSCs and aerosols fully activate 
a) April, $70^{\circ}-90^{\circ} \mathrm{N}$

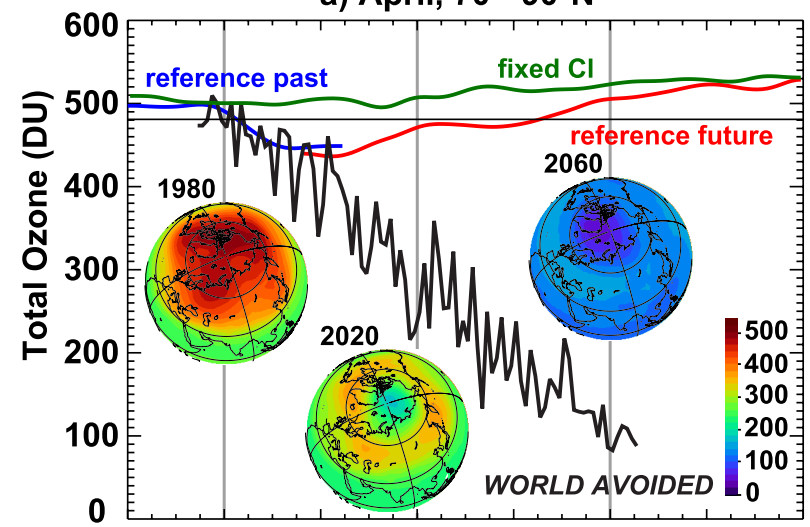

b) October, $70^{\circ}-90^{\circ} \mathrm{S}$

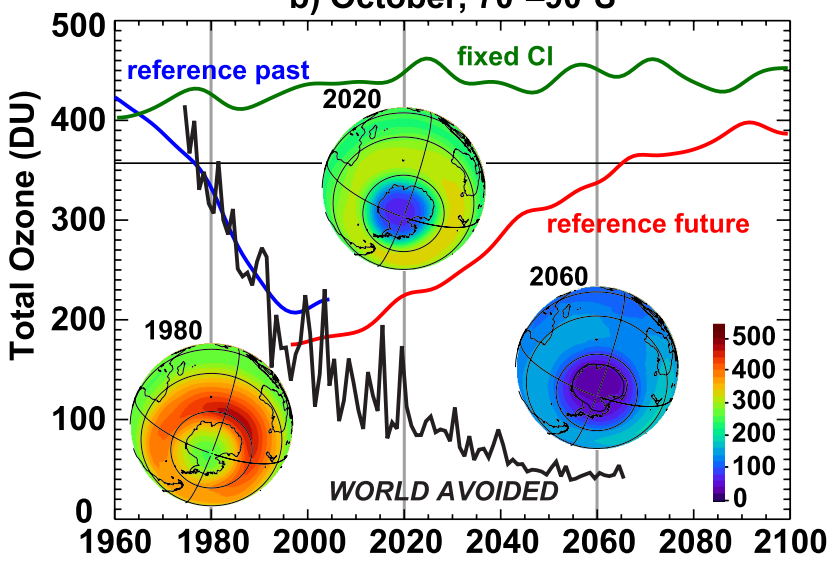

Fig. 4. Total ozone in (a) April for the Arctic and (b) October for the Antarctic for the WORLD AVOIDED (black), reference future (red), fixed chlorine (green), and reference past (blue) simulations. The curves are smoothed with a Gaussian filter with a half-amplitude response of 20 years, except for the WORLD AVOIDED, which is unsmoothed. The inset false-color images show (a) April and (b) October averages for 1980, 2020, and 2060 with 20-DU color increments (see inset scale).

chlorine, leading to massive ozone loss. Hence, in Fig. 4b we see a rapid ozone decline before 2000 with a slower decline after 2000 as ozone losses expand into the regions above and below $50 \mathrm{hPa}$. In contrast, Arctic total ozone decreases linearly because saturation effects do not occur (e.g., Tripathi et al., 2007).

In addition to radical changes in the spring polar column amount in the WORLD AVOIDED simulation, the annual cycle of total ozone over the polar regions is also radically altered. Figure 5 displays the column values versus the day of the year over the Arctic (Fig. 5a) and the Antarctic (Fig. 5b) at 10-year increments from 1980 to 2060, with the addition of 2065. The Arctic (Fig. 5a) peak levels in the early years (1980-1990) occur in the springtime. Large depletions in the Arctic spring become apparent by the late 1990s, and gradually worsen in later years. As seen in Fig. 4a, the April ozone
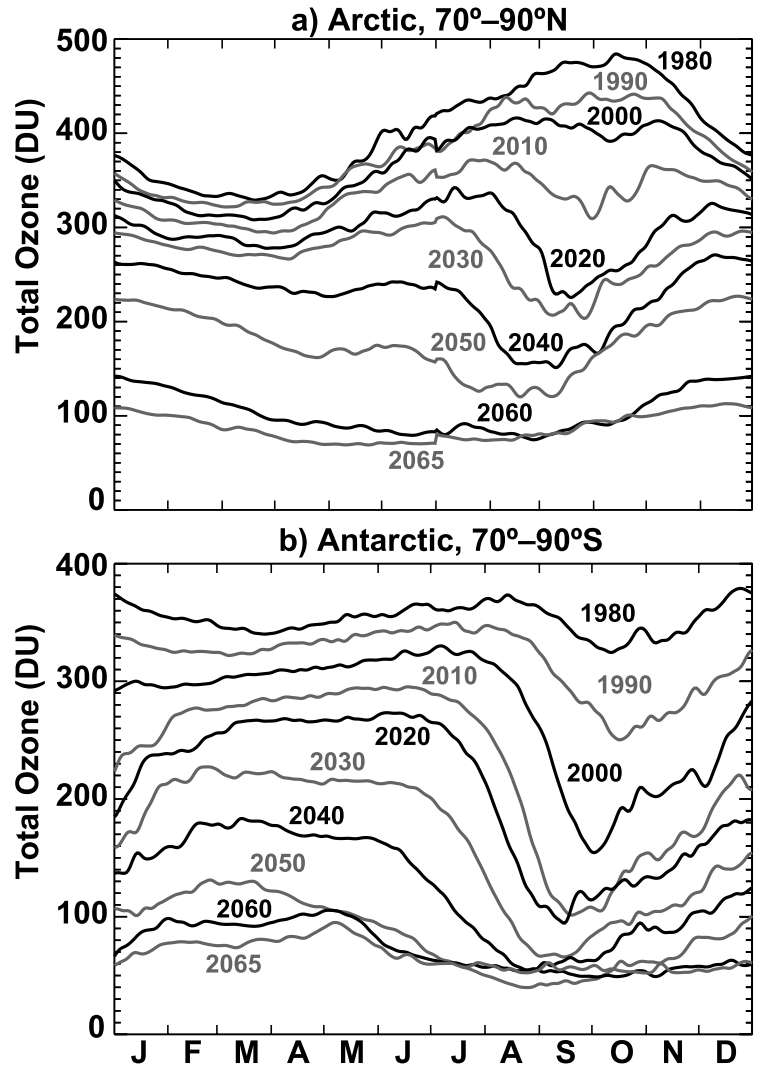

Fig. 5. Total ozone from the WORLD AVOIDED simulation over (a) the Arctic $\left(70^{\circ}-90^{\circ} \mathrm{N}\right.$ average $)$ and (b) the Antarctic $\left(70^{\circ}-90^{\circ} \mathrm{S}\right.$ average) versus day of the year for a selected set of years from 1980 to 2065. The years are alternated black and grey for illustrative purposes. The Arctic values are shifted by 6 months (note the break between 31 December and 1 January) for comparison to the Antarctic.

reaches a 220-DU level in about 2030. The observed autumn through winter increase of ozone is clearly seen in 1980 (Bowman and Krueger, 1985), but by 2020 this has been inverted to a decrease. A comparison of the 1980 values with 2040 reveals a complete phase shift of the annual cycle.

The Antarctic annual cycle (Fig. 5b) shows a worsening spring situation. The development of the ozone hole is clearly seen in the spring by comparison of 1980 to the 1990 and 2000 curves. The ozone hole continues to worsen into the 21st century with lower values and earlier onsets of the minimum value. Also note that the spring-to-summer increase of ozone has weakened by 2030 , thereby creating a year-round ozone hole. This weak summer increase results from the decreased advection into the Antarctic region as ozone is depleted in both the upper stratosphere and midlatitude middle and lower stratosphere. By 2050 the annual cycle of ozone over Antarctica is relatively small because of the very strong in situ depletion and the lack of advective resupply of ozone to the Antarctic region. 


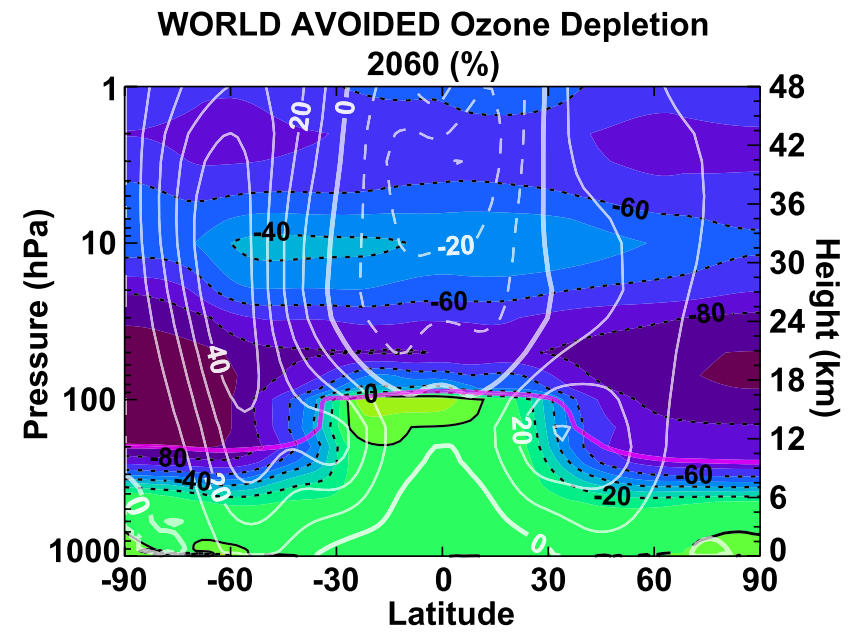

Fig. 6. Percentage total ozone difference between the WORLD AVOIDED and the reference future simulations for a decadal average (2055-2065). The dashed contours are in 20\% increments while colors are in $10 \%$ increments. The magenta line shows the WORLD AVOIDED tropopause. The white lines show the zonal-mean zonal winds (easterlies are dashed) for the WORLD AVOIDED simulation.

The WORLD AVOIDED simulation has its largest losses in two distinct vertical layers: the lower stratosphere (200$30 \mathrm{hPa})$, and in the upper stratosphere $(2 \mathrm{hPa})$. Since most of the ozone is found in the lower stratosphere, the lower stratospheric losses dominate the column losses seen in Fig. 2 through Fig. 5. Figure 6 displays the 2060 difference in annually-averaged ozone losses as a function of altitude and latitude between the WORLD AVOIDED and the reference future simulations. The annually-averaged losses in the 200$30 \mathrm{hPa}$ region of Antarctica exceed $90 \%$ in the region extending out to the edge of the polar vortex (the peak of the zonal mean winds is colocated with the polar vortex edge). Arctic lower stratospheric annually-averaged losses also exceed $90 \%$ by 2060 . In addition to the polar loss, a large tropical lower stratospheric loss $(>70 \%)$ is also observed in the 70 $30 \mathrm{hPa}$ layer. Morgenstern et al. (2008) showed a very similar pattern of upper stratospheric losses and polar losses in comparison to our WORLD AVOIDED 2020 to 2000 differences.

Upper stratospheric losses exceed $60 \%$ over a large latitude width in the $5-0.5 \mathrm{hPa}$ region, with peak losses above $70 \%$ in the midlatitudes. Middle stratosphere losses are somewhat less $(40-60 \%)$ in the 5-3 hPa layer. In addition to the stratospheric losses, ozone losses extend into the troposphere (the tropopause is indicated by the magenta line on Fig. 6). The GEOSCCM model relaxes to a fixed ozone climatology in the troposphere with a 5-day time scale, hence, the decrease of ozone in the troposphere is caused by advection of ozone-depleted air into the troposphere. The contribution of stratospheric ozone loss to the troposphere is likely underestimated, at least seasonally, since ozone's tro-

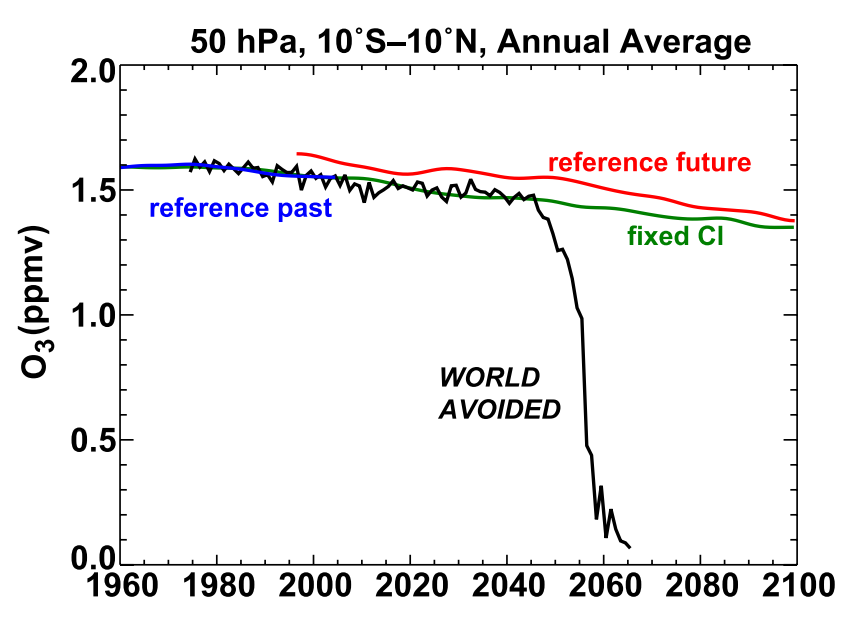

Fig. 7. Annually-averaged ozone $\left(50 \mathrm{hPa}, 10^{\circ} \mathrm{S}-10^{\circ} \mathrm{N}\right)$ for the WORLD AVOIDED (black), reference future (red), fixed chlorine (green), and reference past (blue) simulations. The curves are smoothed with a Gaussian filter with a half-amplitude response of 20 years, except for the WORLD AVOIDED, which is unsmoothed.

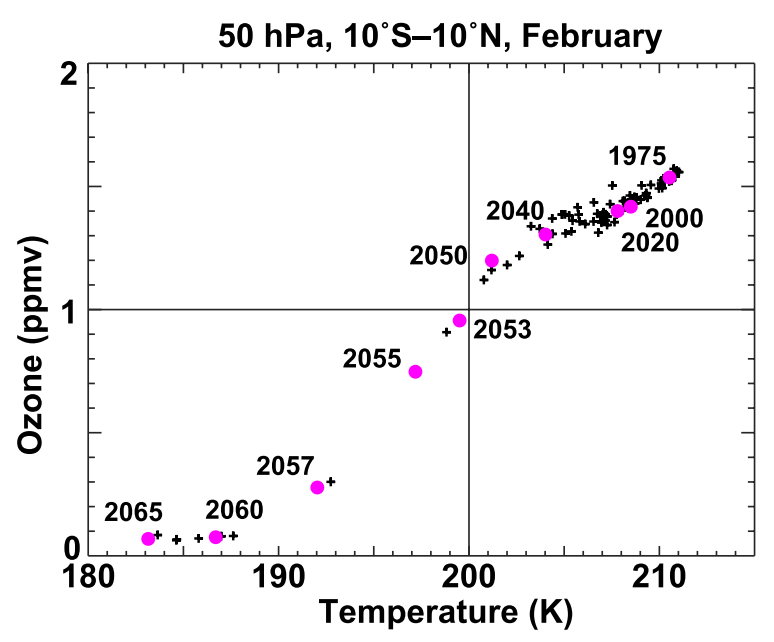

Fig. 8. The February WORLD AVOIDED ozone versus temperature (also at $50 \mathrm{hPa}$ and $10^{\circ} \mathrm{S}-10^{\circ} \mathrm{N}$, as in Fig. 7). Certain years are highlighted in magenta.

pospheric lifetime can be much longer than 5 days during polar night, for example. The small increase of ozone just below the tropical tropopause is probably related to the increased vertical lifting.

The ozone loss in the tropical lower stratosphere occurs extremely rapidly in the WORLD AVOIDED simulation in the six-year period from 2052 through 2058. Figure 7 shows the annual average of ozone in the tropics $\left(10^{\circ} \mathrm{S}-10^{\circ} \mathrm{N}\right)$ at $50 \mathrm{hPa}$ from the WORLD AVOIDED simulation. Ozone shows a slow decline from the 1960s to the 2050 period as the residual circulation accelerates (Oman et al., 2009). Figure 8 shows the February ozone values plotted against 


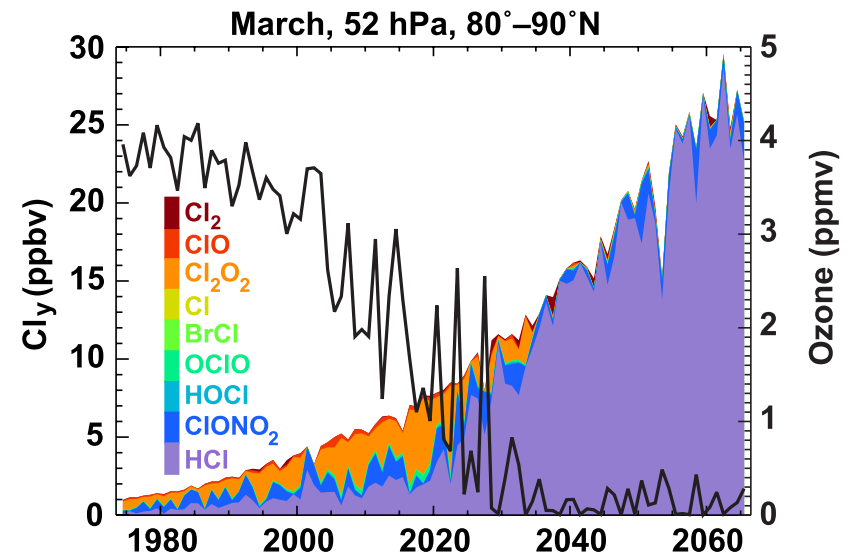

Fig. 9. Arctic lower stratosphere sand chart of $\mathrm{Cl}_{\mathrm{y}}$ versus year from the WORLD AVOIDED simulation for $1 \mathrm{March}, 52 \mathrm{hPa}$, and $80^{\circ}-$ $90^{\circ} \mathrm{N}$. The individual contributions of various species to $\mathrm{Cl}_{\mathrm{y}}$ are shown in color (see color bar). Also shown is ozone averaged over the same region (black line).

the corresponding temperature. The ozone decrease quickly accelerates as temperatures drop below about $200 \mathrm{~K}$ in the 2052-2058 period. This is a result of ozone loss cycles that are accelerated by heterogeneous processes in this period (to be discussed in the next section).

\section{Chemistry}

Stratospheric ozone levels in the WORLD AVOIDED simulation are severely depleted by the chlorine catalytic loss cycles. Furthermore, the relative fractions of chlorine, bromine, nitrogen, and hydrogen compounds are also drastically changed. The $\mathrm{ClO}+\mathrm{ClO}$ and $\mathrm{ClO}+\mathrm{BrO}$ catalytic cycles dominate ozone loss in the Arctic and Antarctic (Molina and Molina, 1987). Figure 9 displays the $\mathrm{Cl}_{\mathrm{y}}$ partitioning versus year in the Arctic $\left(80^{\circ}-90^{\circ} \mathrm{N}\right.$ average, $52 \mathrm{hPa}-$ the model level nearest $50 \mathrm{hPa}$ ) for 1 March of each year. The $\mathrm{Cl}_{\mathrm{y}}$ does not grow smoothly (as shown in Fig. 1) because of year-to-year transport variability and because the $\mathrm{Cl}_{\mathrm{y}}$ is only shown for 1 March. The individual species are indicated by the color bar, with dominant species $\mathrm{HCl}$, chlorine nitrate $\left(\mathrm{ClONO}_{2}\right)$, and chlorine oxide $\left(\mathrm{Cl}_{2} \mathrm{O}_{2}\right)$. Up to about 2025, the reactive chlorine provides a major fraction of the $\mathrm{Cl}_{\mathrm{y}}$, but by 2035 the reactive species are only a minor component with $\mathrm{HCl}$ dominating $\mathrm{Cl}_{\mathrm{y}}$. This region is still largely in polar night (solar zenith angle $>87.7^{\circ}$ ), hence, the reactive $\mathrm{Cl}_{\mathrm{y}}$ is mainly found in $\mathrm{Cl}_{2} \mathrm{O}_{2}$. The ozone levels are indicated by the superimposed black line. Polar lower stratospheric ozone falls below 1 ppmv in the 2020s and remains low through 2065 with some minor variations that are a result of transport and temperature variations (less loss in warmer winters and more loss in colder winters). Comparison of the ozone levels in Fig. 9 with the total ozone in Fig. 4a shows that an Arctic

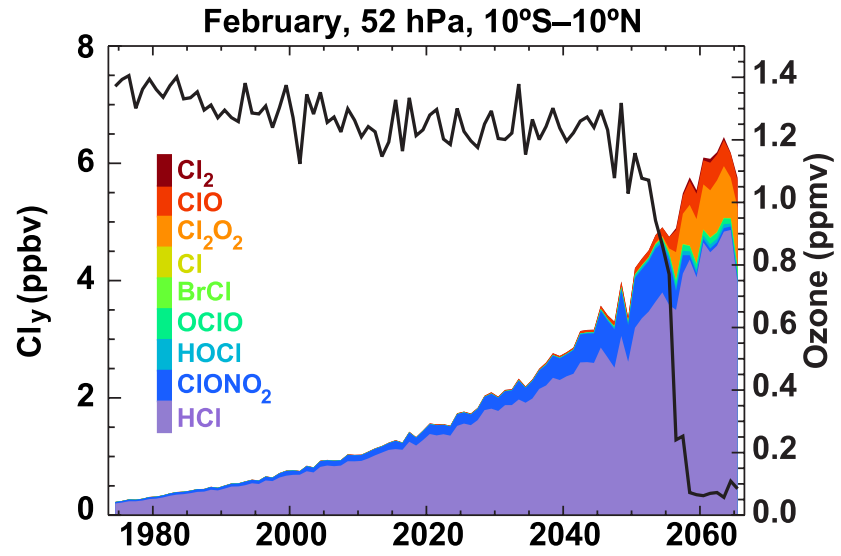

Fig. 10. As in Fig. 9 except for 1 February and $10^{\circ} \mathrm{S}-10^{\circ} \mathrm{N}$.

ozone hole has become well established by 2020 with low insitu ozone, high levels of reactive chlorine species $\left(\mathrm{Cl}_{\mathrm{X}}\right)$, and low column ozone. The very low ozone levels after 2030 are accompanied by the preponderance of $\mathrm{HCl}$ in the $\mathrm{Cl}_{\mathrm{y}}$ reservoir. This $\mathrm{HCl}$ dominance results from the reaction of the $\mathrm{Cl}$ with $\mathrm{CH}_{4}$ and the disappearance of $\mathrm{Cl}_{\mathrm{x}}$ species when ozone levels approach zero (Douglass et al., 1995).

A notable result of the WORLD AVOIDED simulation is the extremely rapid tropical lower stratospheric depletion in the 2052-2058 period (see Fig. 7). Figure 8 shows the strong relationship of temperature to lower stratospheric ozone, suggesting that the rapid ozone loss results from a nonlinear interaction of the cooling of the tropical lower stratosphere and heterogeneous chemistry. Figure 10 displays the tropical lower stratospheric $\mathrm{Cl}_{\mathrm{y}}$ partitioning versus year at $52 \mathrm{hPa}$ and $10^{\circ} \mathrm{S}-10^{\circ} \mathrm{N}$ for 1 February of each year. $\mathrm{HCl}(80-85 \%)$ and $\mathrm{ClONO}_{2}(10-15 \%)$ dominate $\mathrm{Cl}_{\mathrm{y}}$ in the $1975-2050$ period. During the 2052-2058 period, the levels of reactive chlorine $\left(\mathrm{Cl}_{2} \mathrm{O}_{2}\right.$ and $\left.\mathrm{ClO}\right)$ suddenly increase from a few percent to about $20 \%$ of the total, while $\mathrm{ClONO}_{2}$ drops from $20 \%$ to only $1-2 \%$ of the total. Concurrent with the rapid increase of the reactive chlorine, the ozone drops to near zero (black lines in Fig. 7 and Fig. 10). The rapid repartitioning of the chlorine budget results from the increased reactivity of $\mathrm{HCl}$ and $\mathrm{ClONO}_{2}$ on sulfate aerosol particles as the lower stratosphere cools and $\mathrm{Cl}_{\mathrm{y}}$ increases. Such increased reactivity has been observed over Antarctica (Kawa et al., 1997). "Ozone hole" chemistry appears in the tropical lower stratosphere in about 2052, leading to complete lower stratospheric ozone loss by 2058 .

The evolution of water vapor in the WORLD AVOIDED simulation generally follows the $\mathrm{H}_{2} \mathrm{O}$ trends shown by Oman et al. (2009). However, the strong cooling (see Fig. 7) associated with this tropical ozone decrease also leads to a removal of about $1 \mathrm{ppm}$ of water throughout the stratosphere by 2060 . This water is removed in the tropical layer between about $100 \mathrm{hPa}$ and $50 \mathrm{hPa}$. 


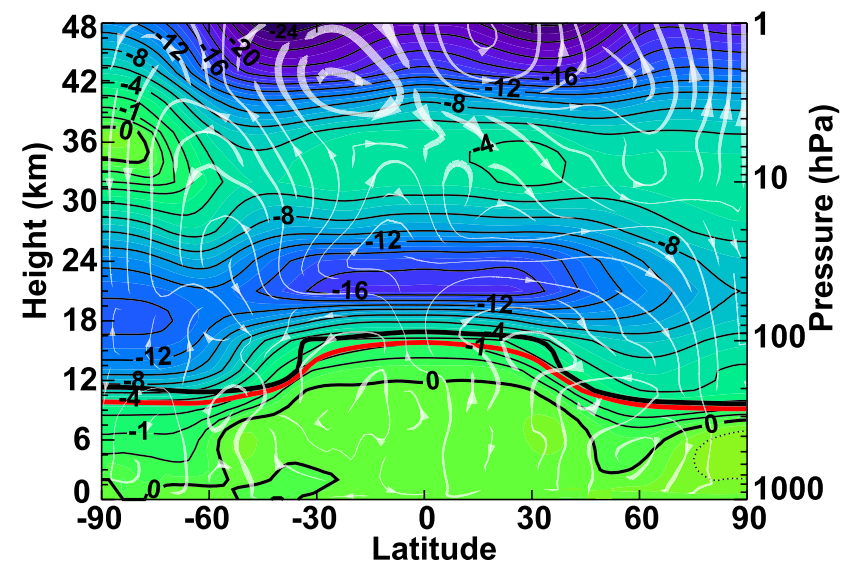

Fig. 11. Annually-averaged temperature difference (K) between the WORLD AVOIDED and the reference future simulations for the 2055-2065 period. Contour increments are $2 \mathrm{~K}$, while color increments are $1 \mathrm{~K}$. The thick black (red) line shows the WORLD AVOIDED (reference future) tropopause. The white lines show streamlines for the residual circulation differences between the WORLD AVOIDED and the reference future simulations over the period. Thicker streamlines indicate increased flow strength.

\section{Dynamics and transport}

The large ozone depletions in the WORLD AVOIDED simulation lead to remarkable changes in dynamics and transport, including large temperature decreases by the middle of the 21st century. Figure 11 displays the temperature change between the WORLD AVOIDED and reference future simulations during the 2055-2065 decade. Cooling is observed everywhere in this simulation except in the troposphere and at $36 \mathrm{~km}$ over Antarctica. The cooling at $1 \mathrm{hPa}$ exceeds $20 \mathrm{~K}$. Shortwave heating at $1 \mathrm{hPa}$ is directly proportional to the ozone concentration. As ozone decreases the shortwave heating decreases and the upper stratospheric temperature decreases.

The warming at $36 \mathrm{~km}$ over Antarctica in Fig. 11 results from the dynamical heating caused by the increased downwelling. The white stream lines in the plot show the difference between the residual circulations in the WORLD $A V O I D E D$ and reference future simulations. A lifting leads to additional cooling, while sinking motion causes a dynamical warming. The thick black and red lines show the positions of the tropopause in both the WORLD AVOIDED and reference future, respectively. This tropopause is defined with respect to a change in Brunt-Väisällä frequency. As is clear from the plot, the tropopause increases in altitude at all latitudes as a result of the stratospheric cooling.

The WORLD AVOIDED cooling in the tropical lower stratosphere results from the combined effects of an increase of the vertical lifting (note the residual circulation streamlines in Fig. 11) and decreased shortwave heating in the

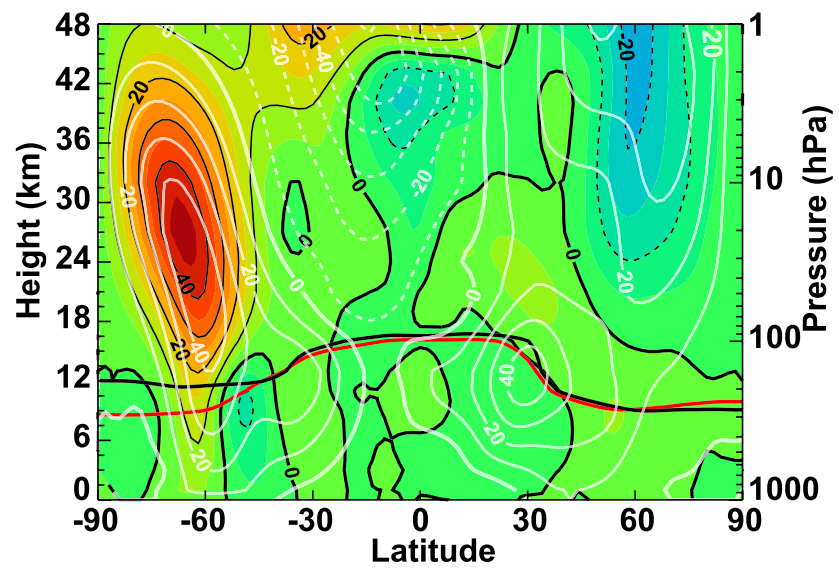

Fig. 12. Average January zonal-mean zonal wind differences $\left(\mathrm{m} \mathrm{s}^{-1}\right)$ between the WORLD AVOIDED and the reference future simulations for the 2055-2065 period. Contour increments are $10 \mathrm{~m} \mathrm{~s}^{-1}$, while color increments are $5 \mathrm{~m} \mathrm{~s}^{-1}$. The thick black (red) line shows the WORLD AVOIDED (reference future) tropopause. The white lines show average January zonal-mean wind in the WORLD AVOIDED simulation over the period.

tropical lower stratosphere. The shortwave heating remains roughly constant up to 2045 because of the balancing effect of the UV penetration and ozone changes. As ozone decreases in the upper stratosphere greater UV flux penetrates to $50 \mathrm{hPa}$, but as 50 -hPa ozone decreases the UV flux absorption decreases, resulting in only very small changes to the shortwave heating. As the increasing tropical lower stratosphere lifting continues to cool the lower stratosphere, tropical lower stratospheric temperatures cool below the threshold for forming stratospheric clouds and heterogeneous chemical processes lead to more ozone loss. The larger ozone losses then lead to less shortwave heating which further cools the lower stratosphere, producing a positive feedback that accelerates the ozone loss. This positive feedback leads to the complete collapse of lower stratospheric ozone between 2052 and 2058 (Fig. 7). This same ozone collapse is also simulated in the coupled 2-D model WORLD AVOIDED.

Changes of ozone and temperature result in zonal-mean zonal wind changes. Figure 12 displays the change during January between the reference future and WORLD AVOIDED simulations averaged over the 2055-2065 period (with the mean January WORLD AVOIDED zonal winds superimposed as the white lines). In the Southern Hemisphere (SH) the mid-summer easterlies in the reference future simulation are replaced with westerlies extending to $1 \mathrm{hPa}$ in the WORLD AVOIDED simulation. The colder SH polar stratosphere leads to a large increase in the tropopause altitude. At $10 \mathrm{hPa}$ and $65^{\circ} \mathrm{S}$ the change is approximately $45 \mathrm{~m} \mathrm{~s}^{-1}$, while the WORLD AVOIDED mean winds are slightly higher than $40 \mathrm{~m} \mathrm{~s}^{-1}$. The complete reversal of the usual summer easterlies indicates that the $\mathrm{SH}$ stratosphere has slipped into a 
permanent winter across the seasons by 2065 . The Northern Hemisphere (NH) winter polar vortex is slightly weaker in mid-winter in the WORLD AVOIDED, but this difference is not statistically significant. In contrast to the $\mathrm{SH}$, the $\mathrm{NH}$ does switch to a summer or easterly circulation in the spring because the $\mathrm{NH}$ tropospheric wave forcing of the stratosphere is very large in the spring. However, the NH summer stratosphere is significantly colder in the summer because of the lack of shortwave heating. In addition to these polar vortex results, the upper side of the subtropical jet $\left(30^{\circ} \mathrm{N}\right.$, $70 \mathrm{hPa}$ ) is about $5 \mathrm{~m} \mathrm{~s}^{-1}$ stronger in January.

The large ozone losses also induce changes in the transport of trace species in the stratosphere. Figure 13 shows the difference in mean age-of-air between the WORLD AVOIDED and reference future simulations during the 2055-2065 period. The mean age is calculated in the model by advecting a tracer that increases linearly with time at the surface, and then computing the time difference at various points of the atmosphere with this age tracer at the tropical tropopause $\left(100 \mathrm{hPa}, 20^{\circ} \mathrm{S}-20^{\circ} \mathrm{N}\right)$. Oman et al. (2009) have recently shown that there is a near linear decrease of mean age over the late 20th and 21 st centuries in the reference past and reference future simulations. In the WORLD AVOIDED simulation, the large ozone depletion leads to additional decreases of the mean age-of-air by more than one year in the extratropical stratosphere. Much of this age decrease arises from the increase of the vertical lifting. The residual circulation is shown in Figs. 11 and 13 as the transparent white arrowed lines. Vertical lifting in the tropics $\left(50 \mathrm{hPa}, 10^{\circ} \mathrm{S}-10^{\circ} \mathrm{N}\right)$ has changed from $15 \mathrm{~m} \mathrm{~d}^{-1}$ in the reference future to $25 \mathrm{~m} \mathrm{~d}^{-1}$ in the WORLD AVOIDED simulation (a $65 \%$ increase in upwelling). In addition, there is decreased rising motion above $50 \mathrm{hPa}$ (point A in Fig. 13). This fresh young air from the troposphere then spills poleward decreasing the mean age in the extratropics (point B).

Circulation changes are also apparent in the middle-toupper stratosphere. The downward circulation (point $\mathrm{C}$ in Fig. 13) is caused by the changes in the mean zonal winds. As noted by Stolarski et al. (2006), the ozone losses caused by the Antarctic ozone hole help the polar vortex persist into the summer period. The presence of westerly winds in the late spring and summer allows planetary waves to propagate vertically and deposit easterly momentum in the upper stratosphere, inducing a poleward and downward circulation that would not normally be present. This increased poleward and downward circulation is exacerbated in the WORLD AVOIDED simulation by the additional ozone losses. The opposite situation is found in the NH (point D). The planetary wave deposition of easterly momentum is reduced in the upper stratosphere, reducing the poleward and downward circulation. The small horizontal and vertical gradients of mean age-of-air in the middle-to-upper stratosphere lead to only small changes of age in these regions.

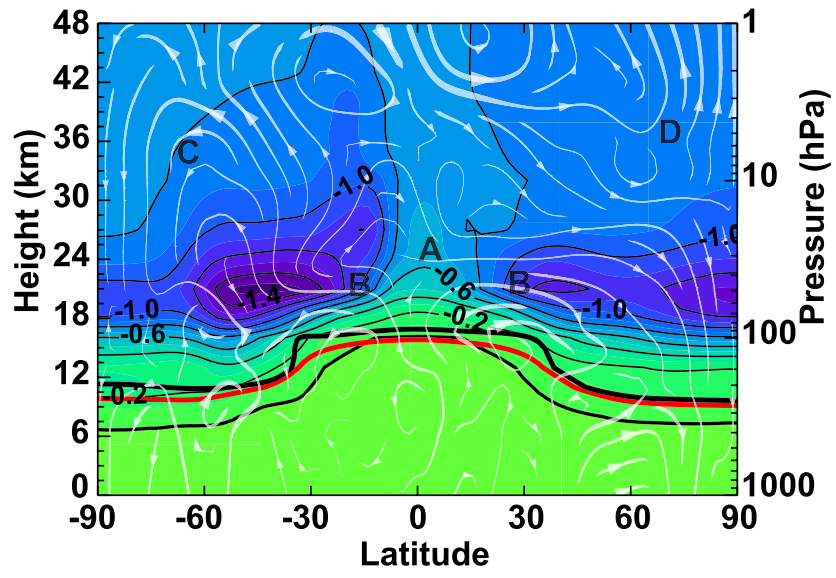

Fig. 13. As in Fig. 11 except for mean age-of-air differences in units of years. Contour increments are 0.2 years, while color increments are 0.1 years. Letters indicate points of interest in the text.

\section{UV changes}

As a result of the large ozone depletions, the surface UV reaches extreme levels. To illustrate these changes we have calculated the surface UV flux in the northern midlatitudes at the height of summer (2 July at local noon) for the WORLD AVOIDED simulation. UV calculations were done for a cloud-free atmosphere using Atmospheric Laboratory for Applications and Science 3 (ATLAS-3) extraterrestrial (ET) solar flux and the Total Ozone Mapping Spectrometer radiative transfer (RT) code (TOMRAD). In the TOMRAD code, the atmosphere is assumed to be plane-stratified, with Rayleigh scattering (Bates, 1984), WORLD AVOIDED ozone and temperature profiles, and prescribed surface albedo. The solution method is based on the successive iteration of the auxiliary equation of the RT (Dave, 1964, 1965; Dave and Furukawa, 1966). The calculations of atmospheric transmission were done at the original sampling wavelengths of the ozone cross-sections measured by Bass and Paur (1985) and Paur et al. (1985), with steps $\approx 0.05 \mathrm{~nm}$. The transmittance values were linearly interpolated to the vacuum wavelengths of the high resolution ET solar flux data (ATLAS-3 Solar U1traviolet Spectral Irradiance Monitor ET) and multiplied by the ET spectrum. The TOMRAD RT model compared well with spectral irradiance measurements and the output from other RT models run during the International Photolysis Frequency Measurement and Model Intercomparison campaign (Bais et al., 2003).

Figure 14 displays the flux as a function of wavelength for 1980, 2040, and 2065. The vast majority of the UV increase occurs at wavelengths less than $310 \mathrm{~nm}$. Figure 15 shows the ratio of the 2000,2020, 2040, and 2065 UV flux to the 1980 UV flux. At wavelengths below $308 \mathrm{~nm}$ the UV flux has more than doubled by 2065 , and the flux has increased by a factor of 1000 for wavelengths less than $291 \mathrm{~nm}$. At $280 \mathrm{~nm}$ in 


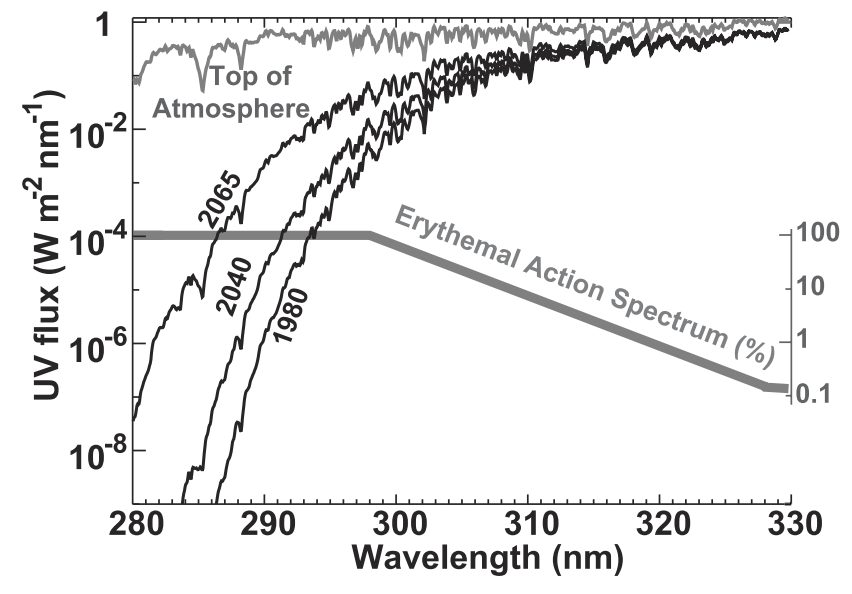

Fig. 14. UV flux $\left(\mathrm{W} \mathrm{m}^{-2} \mathrm{~nm}^{-1}\right)$ is shown for the WORLD AVOIDED simulation in 1980, 2040, and 2065 (thick black lines). The UV flux is calculated using the July $30^{\circ}-50^{\circ} \mathrm{N}$ zonal-mean ozone and temperature profiles, and assuming a time of local noon on 2 July. The thick grey line shows the erythemal (sunburn) action spectrum (right hand axis). The thin darker grey line shows UV flux at the top of the atmosphere.

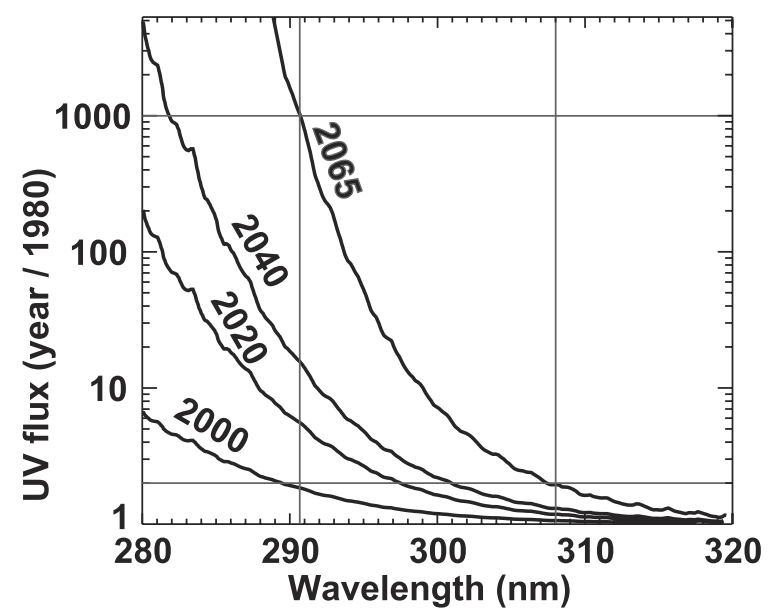

Fig. 15. The ratio of the UV flux (from Fig. 14) for 2000, 2020, 2040 , and 2065 to its value in 1980 . The horizontal grey lines indicate a doubling and a factor of 1000 from the 1980 conditions. The vertical lines indicate where the 2065 curve crosses these two levels.

2065, the WORLD AVOIDED UV flux is $10^{9}$ times stronger than the 1980 flux level (off scale).

We have calculated the UV index for midlatitude $\mathrm{NH}$ conditions in mid-summer (a relatively densely populated zone on the globe). Figure 16 shows this UV index for the WORLD AVOIDED, reference future, and fixed chlorine simulations. For mid-summer clear-sky conditions, the UV index is normally very high at local noon; with a typical time to produce a perceptible sun burn (type II skin) of about 10-

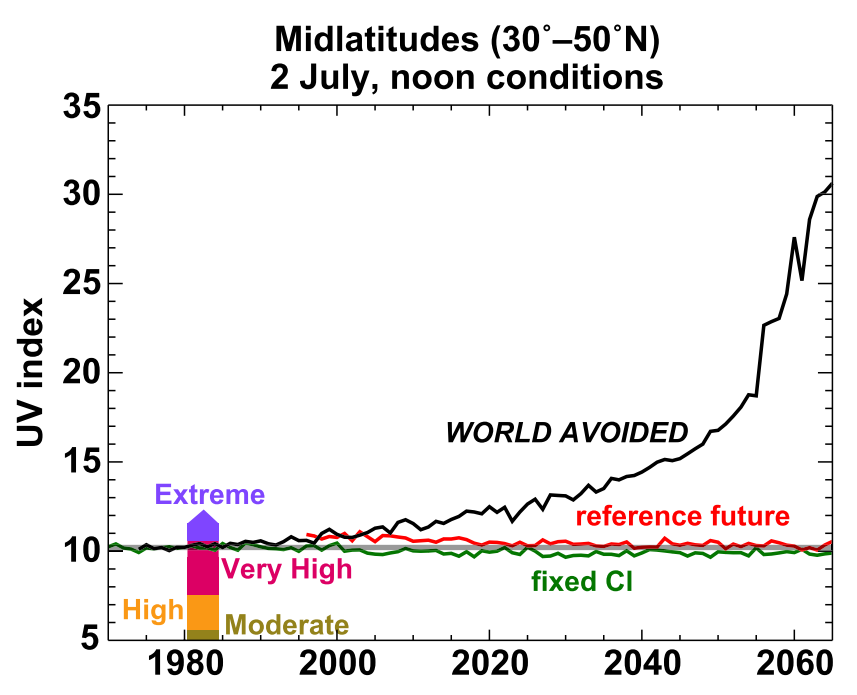

Fig. 16. UV index versus year for the WORLD AVOIDED (black), reference future (red), and fixed chlorine (green) simulations. As with Fig. 14, the UV index is calculated using the July $30^{\circ}-50^{\circ} \mathrm{N}$ zonal-mean ozone, and assuming a time of local noon on 2 July. The standard UV index "risk" scale is also superimposed on the bottom left. The horizontal grey line shows the 1975-1985 average of the UV index from the fixed chlorine simulation.

20 min. The mid-summer period has the highest UV index over the course of the year. The differences between the reference future and fixed chlorine simulations show increases on the order of $5-10 \%$ by 2000 . The WORLD AVOIDED simulation has the UV index nearing 15 by 2040 and exceeding a value of 30 by 2065 . This extreme value of the UV index would reduce the perceptible sunburn time from approximately $15 \mathrm{~min}$ to about $5 \mathrm{~min}$. The UV index values also increase by 2065 to large values at both the eqator (33 in early March) and SH midlatitudes (35 at $40 \mathrm{~S}$ for midJanuary).

These extreme UV increases would also lead to large increases of skin cancer (Slaper et al., 1996). In the same manner as estimating the UV index, we apply a DNA damage action spectrum to our UV spectrum calculations (Setlow, 1974). The DNA damaging UV for the NH midlatitudes increases by approximately 550\% between 1980 and 2065 .

\section{Summary}

In this study we have simulated the effects on the stratosphere of a steady growth of ozone-depleting substances and compared those results to the normal expectations of the evolution of the stratosphere in the 21st century. As was suggested by the original Molina and Rowland (1974) study on CFCs in the stratosphere, large concentrations of ODSs in the atmosphere would have virtually destroyed the majority of the ozone layer by 2065 (global annual average losses $>60 \%$ ). 
Very large ozone losses are computed at all latitudes in the stratosphere of the WORLD AVOIDED simulation. The largest losses in both percentage and Dobson Units are in the polar latitudes. However, surprisingly large losses also occur in tropical latitudes as a result of heterogeneous chemical processes that occur in the 2052-2058 period. This "polar chemistry" in the tropics begins to appear in the lower stratosphere as a consequence of cooling resulting from increased vertical lifting.

Most of the ozone depletion occurs in the lower stratosphere $(12-24 \mathrm{~km})$ and the upper stratosphere $(\approx 42 \mathrm{~km})$. Losses inside the polar vortex in both hemispheres exceed $90 \%$ by 2065 . At $20 \mathrm{~km}$, annual average tropical levels are reduced by $80 \%$. Ozone losses in the upper stratosphere exceed $60 \%$. Middle stratosphere ozone losses are smaller, but still greater than $40 \%$.

As in current observations, the largest losses occur in the spring polar regions. Over Antarctica, the ozone hole develops quickly in the 1980-2000 period, with somewhat slower trends after 2000 as a result of the complete ozone destruction in the lower stratosphere. October column values drop from $400 \mathrm{DU}$ (somewhat higher than historic observations) to values of about $60 \mathrm{DU}$ by 2065 (85\% loss). By 2040, the SH stratosphere ozone values are so low that interannual variability of the dynamics and transport has virtually no impact on total ozone, such that the total ozone internannual variability is near zero. In the Arctic, ozone declines are more linear with April total ozone dropping from values near $500 \mathrm{DU}$ to about $100 \mathrm{DU}$ in 2065 (an 80\% decline). The annual ozone mixing ratios in the Antarctica and Arctic lower stratosphere (15-20 km) are nearly zero.

The severe ozone depletions lead to interesting dynamical changes. The SH westerly circulation persists virtually yearround by 2035 , although temperatures still exceed $195 \mathrm{~K}$ in the late spring. This westerly circulation allows the vertical propagation of planetary scale waves (westerly winds are necessary for the vertical propagation of large scale Rossby waves) (Charney and Drazin, 1961). The deposition of easterly momentum from these waves then drives a poleward and downward circulation. In the $\mathrm{NH}$ stratosphere, the midwinter dynamical changes are surprisingly small. The stratospheric polar night jet remains virtually the same. By 2055 , the vertical circulation in the tropics $\left(50 \mathrm{hPa}, 10^{\circ} \mathrm{S}-10^{\circ} \mathrm{N}\right)$ has increased by about $65 \%$. This increased upwelling cools the lower stratosphere leading to the onset of heterogeneous chemistry and the collapse of ozone in the lower stratosphere in the 2052-2058 period.

Our WORLD AVOIDED simulation is limited in a few respects. First, the simulation was performed with specified SSTs that were simulated by the NCAR CCM3 using the IPCC A1b scenario. Hence, our tropospheric temperatures do not correctly respond to the increased $\mathrm{CFC}$ radiative forcing or stratospheric changes. Second, the model does not include tropospheric chemistry (i.e., the tropospheric ozone values are relaxed to the climatology of Logan, 1999) and thus tropospheric ozone changes are not discussed in this study. Because tropospheric ozone is not explicitly modeled, the radiative forcing on the troposphere of tropospheric ozone is not correct. Since the tropospheric climage changes are not correctly simulated, the complete tropospheric effect on the stratosphere is not correctly simulated (e.g., the changes in vertical wave propagation from the troposphere to the stratosphere). Third, since the tropospheric chemistry is not modeled, the simulated surface UV changes are limited to those only caused by the stratosphere. Fourth, the GEOSCCM is forced by scenario estimates of surface mixing ratios of both greenhouse gases and CFCs. The increased stratospheric circulation will shorten the lifetimes of CFCs. The increased UV that penetrates to the troposphere might increase the hydroxyl radical, increasing the oxidizing capacity of the troposphere and thereby shortening the lifetimes of gases such as $\mathrm{CH}_{4}$ and HCFCs. Hence, feedback of the UV and circulation would affect the evolution of both climate and ozone depleting gases.

Acknowledgements. This work was supported under the NASA Atmospheric Chemistry Modeling and Analysis Program and the Modeling, Analysis, and Prediction Program. GEOS CCM simulations were performed on NASA's Columbia platform using resources provided by NASA's High-End Computing initiative. We are also grateful for the helpful comments provided by David Fahey and several reviewers.

Edited by: M. Dameris

\section{References}

Anderson, J., Russell, III, J. M., Solomon, S., and Deaver, L. E.: Halogen Occultation Experiment confirmation of stratospheric chlorine decreases in accordance with the Montreal Protocol, J. Geophys. Res., 105(D4), 4483-4490, doi:10.1029/1999JD901075, 2000.

Bais, A. F., Madronich, S., Crawford, J., Hall, S. R., Mayer, B., van Weele, M., Lenoble, J., Calvert, J. G., Cantrell, C. A., Shetter, R. E., Hofzumahaus, A., Koepke, P., Monks, P. S., Frost, G., McKenzie, R., Krotkov, N., Kylling, A., Swartz, W. H., Lloyd, S., Pfister, G., Martin, T. J., Roeth, E.-P., Griffioen, E., Ruggaber, A., Krol, M., Kraus, A., Edwards, G. D., Mueller, M., Lefer, B. L., Johnston, P., Schwander, H., Flittner, D., Gardiner, B. G., Barrick, J., and Schmitt, R.: International Photolysis Frequency Measurement and Model Intercomparison (IPMMI): Spectral actinic solar flux measurements and modeling, J. Geophys. Res., 108(D16), 8543, doi:10.1029/2002JD002891, 2003.

Bass, A. M. and Paur, R. J.: The ultraviolet cross-sections of ozone: I. The measurements, Atmospheric Ozone: Proceedings of the Quadrennial Ozone Symposium held in Halkidiki, Greece, 3-7 September 1984, edited by: Zerefos, C. S. and Ghazi, A., Reidel, Dordrecht, Holland, 606-610, 1985.

Bates, D. R.: Rayleigh scattering by air, Planet. Space Sci., 32(6), 785-790, doi:10.1016/0032-0633(84)90102-8, 1984.

Bosilovich, M. G., Schubert, S. D., and Walker, G. K.: Global changes of the water cycle intensity, J. Climate, 18(10), 15911608, doi:10.1175/JCLI3357.1, 2005. 
Bowman, K. P. and Krueger, A. J.: A global climatology of total ozone from the Nimbus 7 Total Ozone Mapping Spectrometer, J. Geophys. Res., 90(D5), 7967-7976, doi:10.1175/JD090iD05p07967, 1985.

Charney, J. G. and Drazin, P. G.: Propagation of planetary-scale disturbances from the lower into the upper atmosphere, J. Geophys. Res., 66(1), 83-109, doi:10.1175/JZ066i001p00083, 1961.

Chipperfield, M. P., Randel, W. J., (lead authors), Bodeker, G. E., Dameris, M., Fioletov, V. E., Friedl, R. R., Harris, N. R. P., Logan. J. A., McPeters, R. D., Muthama, N. J., Peter, T., Shepherd, T. G., Shine, K .P., Solomon, S., Thomason, L. W., and Zawodny, J. M.: Global ozone: Past and future, Chapter 1, Scientific assessment of ozone depletion: 2002, Global Ozone Research and Monitoring Project, Report No. 47, Geneva, 2003.

Collins, W. D., Bitz, C. M., Blackmon, M. L., Bonan, G. B., Bretherton, C. S., Carton, J. A., Chang, P., Doney, S. C., Hack, J. J., Henderson, T. B., Kiehl, J. T., Large, W. G., McKenna, D. S., Santer, B. D., and Smith, R. D.: The Community Climate System Model Version 3 (CCSM3), J. Climate, 19(11), 21222143, doi:10.1175/JCLI3761.1, 2006.

Considine, D. B., Douglass, A. R., Connell, P. S., Kinnison, D. E., and Rotman, D. A.: A polar stratospheric cloud parameterization for the global modeling initiative three-dimensional model and its response to stratospheric aircraft, J. Geophys. Res., 105(D3), 3955-3973, 10.1029/1999JD900932, 2000.

Daniel, J. S., Velders, G. J. M. (lead authors), Douglass, A. R., Forster, P. M. D., Hauglustaine, D. A., Isaksen, I. S. A., Kuijpers, L. J. M., McCulloch, A., and Wallington, T. J.: Halocarbon scnarios, ozone depletion potentials, and global warming potentials, Chapter 8, Scientific assessment of ozone depletion: 2006, Global Ozone Research and Monitoring Project, Report No. 50, Geneva, 2007.

Danilin, M. Y., Sze, N.-D., Ko, M. K. W., Rodriguez, J. M., and Prather, M. J.: Bromine-chlorine coupling in the Antarctic ozone hole, Geophys. Res. Lett., 23(2), 153-156, doi:10.1029/95GL03783, 1996.

Dave, J. V.: Meaning of successive iteration of the auxiliary equation in the theory of radiative transfer, Astrophys. J., 140, 12921303, 1964.

Dave, J. V.: Multiple scattering in a non-homogeneous, Rayleigh atmosphere, J. Atmos. Sci. 22(3), 273-279, doi:10.1175/15200469(1965)022<0273:MSIANH > 2.0.CO;2, 1965.

Dave, J. V. and Furukawa, P. M.: Scattered radiation in the ozone absorption bands at selected levels of a terrestrial, Rayleigh atmosphere, Meteorological Monographs, 7, 353 pp., 1966.

Douglass, A. R., Schoeberl, M. R., Stolarski, R. S., Waters, J. W., Russell, III, J. M., Roche, A. E., and Massie, S. T.: Interhemispheric differences in springtime production of $\mathrm{HCl}$ and $\mathrm{ClONO}_{2}$ in the polar vortices, J. Geophys. Res., 100(D7), 13967-13978, doi:10.1029/95JD00698, 1995.

Douglass, A. R. and Kawa, S. R.: Contrast between 1992 and 1997 high-latitude spring Halogen Occultation Experiment observations of lower stratospheric HCl, J. Geophys. Res., 104(D15), 18739-18754, doi:10.1029/1999JD900281, 1999.

Eyring V., Butchart, N., Waugh, D. W., Akiyoshi, H., Austin, J., Bekki, S., Bodeker, G. E., Boville, B. A., Brühl, C., Chipperfield, M. P., Cordero, E., Dameris, M., Deushi, D., Fioletev, V. E., Frith, S. M., Garcia, R. R., Gettelman, A., Giorgetta, M. A., Grewe, V., Jourdain, L., Kinnison, D. E., Mancini, E., Manzini,
E., Marchand, M., Marsh, D. R., Nagashima, T., Newman, P. A., Nielsen, J. E., Pawson, S., Pitari, G., Plummer, D. A., Rozanov, E., Schraner, M., Shepherd, T. G., Shibata, K., Stolarski, R. S., Struthers, H., Tian, W., and Yoshiki, M.: Assessment of temperature, trace species, and ozone in chemistry-climate model simulations of the recent past, J. Geophys. Res., 111, D22308, doi:10.1029/2006JD007327, 2006.

Eyring V., Waugh, D. W., Bodeker, G. E., Cordero, E., Akiyoshi, H., Austin, J., Beagley, S. R., Boville, B. A., Braesicke, P., Brühl, C., Butchart, N., Chipperfield, M. P., Dameris, M., Deckert, R., Deushi, D., Frith, S. M., Garcia, R. R., Gettelman, A., Giorgetta, M. A., Kinnison, Mancini, E., Manzini, E., Marsh, D. R., Matthes, S., Nagashima, T., Newman, P. .A, Nielsen, J. E., Pawson, S., Pitari, G., Plummer, D. A., Rozanov, E., Schraner, M., Scinocca, J. F., Semeniuk, K., Shepherd, T. G., Shibata, K., Steil, B., Stolarski, R. S., Tian, W., and Yoshiki, M.: Multimodel projections of stratospheric ozone in the 21st century, J. Geophys. Res., 112, D16303, doi:10.1029/2006JD008332, 2007.

Fleming, E. L., Jackman, C. H., Stolarski, R. S., and Considine, D. B.: Simulation of stratospheric tracers using an improved empirically based two-dimensional model transport formulation, J. Geophys. Res., 104(D19), 23911-23934, doi:10.1029/1999JD900332, 1999.

Froidevaux, L., Livesey, N. J., Read, W. G., Salawitch, R. J., Waters, J. W., Drouin, B., MacKenzie, I. A., Pumphrey, H. C., Bernath, P., Boone, C., Nassar, R., Montzka, S., Elkins, J., Cunnold, D., and Waugh, D.: Temporal decrease in upper atmospheric chlorine, Geophys. Res. Lett., 33, L23812, doi:10.1029/2006GL027600, 2006.

Garcia, R. R.: Parameterization of planetary wave breaking in the middle atmosphere, J. Atmos. Sci., 48(11), 1405-1419, doi:10.1175/1520-0469(1991)048<1405:POPWBI > 2.0.CO;2, 1991.

Garcia, R. R. and Boville, B. A.: "Downward control" of the mean meridional circulation and temperature distribution of the polar winter stratosphere, J. Atmos. Sci., 51(15), 2238-2245, doi:10.1175/1520-0469(1994)051<2238:COTMMC>2.0.CO;2, 1994.

Houghton, J. T., Jenkins, G. J., and Ephraums, J. J. (Eds.): Climate Change: The IPCC Scientific Assessment, Cambridge Univ. Press, Cambridge, UK, 365 pp., 1990.

Houghton, J. T., Ding, Y., Griggs, D. J., Noguer, M., van der Linden, P. J., Dai, X., Maskell, K., and Johnson, C. A. (Eds.): Climate Change 2001: The Scientific Basis, Cambridge Univ. Press, Cambridge, UK, 881 pp., 2001.

Hudson, R. D. and Reed, E. I (Eds.): The stratosphere: Present and future, NASA Ref. Pub. 1049, Washington, D.C., 432 pp., 1979.

Jackman, C. H., Fleming, E. L., Chandra, S., Considine, D. B., and Rosenfield, J. E.: Past, present, and future modeled ozone trends with comparisons to observed trends, J. Geophys. Res., 101(D22), 28753-28767, doi:10.1029/96JD03088, 1996.

Johns, T. C., Durman, C. F., Banks, H. T., Roberts, M. J., McLaren, A. J., Ridley, J. K., Senior, C. A., Williams, K. D., Jones, A., Rickard, G. J., Cusack, S., Ingram, W. J., Crucifix, M., Sexton, D. M. H., Joshi, M. M., Dong, B.-W., Spencer, H., Hill, R. S. R., Gregory, J. M., Keen, A. B., Pardaens, A. K., Lowe, J. A., BodasSalcedo, A., Stark, S., and Searl, Y.: The new Hadley Centre climate model (HadGEM1): Evaluation of coupled simulations, J. Climate, 19(7), 1327-1353, doi:10.1175/JCLI3712.1, 2006. 
Kawa, S. R., Newman, P. A., Lait, L. R., Schoeberl, M. R., Stimpfle, R. M., Kohn, D. W., Webster, C. R., May, R. D., Baumgardner, D., Dye, J. E., Wilson, J. C., Chan, K. R., and Loewenstein, M.: Activation of chlorine in sulfate aerosol as inferred from aircraft observations, J. Geophys. Res., 102(D3), 3921-3933, doi:10.1175/96JD01992, 1997.

Kiehl, J. T., Hack, J. J., Bonan, G. B., Boville, B. A., Williamson, D. L., and Rasch, P. J.: The National Center for Atmospheric Research Community Climate Model: CCM3, J. Climate, 11(6), 1131-1149, doi:10.1175/15200442(1998)011<1131:TNCFAR>2.0.CO;2, 1998.

Lary, D. J., Waugh, D. W., Douglass, A. R., Stolarski, R. S., Newman, P. A., and Mussa, H.: Variations in stratospheric inorganic chlorine between 1991 and 2006, Geophys. Res. Lett., 34, L21811, doi:10.1029/2007GL030053, 2007.

Lin, S.-J.: A “vertically Lagrangian” finite-volume dynamical core for global models, Mon. Weather Rev., 132(10), 2293-2307, doi:10.1175/1520-0493(2004)132<2293:AVLFDC > 2.0.CO;2, 2004.

Logan, J. A.: An analysis of ozonesonde data for the troposphere: Recommendations for testing 3-D models and development of a gridded climatology for tropospheric ozone, J. Geophys. Res., 104(D13), 16115-16150, doi:10.1029/1998JD100096, 1999.

Molina, M. J. and Rowland, F. S.: Stratospheric sink for chlorofluoromethanes: Chlorine atom catalyzed destruction of ozone, Nature, 249, 810-812, doi:10.1038/249810a0, 1974.

Molina, L. T. and Molina, M. J.: Production of chlorine oxide $\left(\mathrm{Cl}_{2} \mathrm{O}_{2}\right)$ from the self-reaction of the chlorine oxide $(\mathrm{ClO})$ radical, J. Phys. Chem., 91(2), 433-436, doi:10.1021/j100286a035, 1987.

Montzka, S. A., Butler, J. H., Myers, R. C., Thompson, T. M., Swanson, T. H., Clarke, A. D., Lock, L. T., and Elkins, J. W.: Decline in the tropospheric abundance of halogen from halocarbons: Implications for stratospheric ozone depletion, Science, 272(5266), 1318-1322, doi:10.1126/science.272.5266.1318, 1996.

Montzka, S. A., Fraser, P. J., (lead authors), Butler, J. H., Connell, P. S., Cunnold, D. M., Daniel, J. S., Derwent, R. G., Lal, S., McCulloch, A., Oram, D. E., Reeves, C. E., Sanhueza, E., Steele, L. P., Velders, G. J., M., Weiss, R. F., and Zander, R. J.: Controlled substances and other source gases, Chapter 1, Scientific assessment of ozone depletion: 2002, Global Ozone Research and Monitoring Project, Report No. 47, Geneva, 2003.

Morgenstern, O., Braesicke, P., Hurwitz, M. M., O'Connor, F. M., Bushell, A. C., Johnson, C. E., and Pyle, J. A.: The world avoided by the Montreal Protocol, Geophys. Res. Lett., 35, L16811, doi:10.1029/2008GL034590, 2008.

Newman, P. A., Daniel, J. S., Waugh, D. W., and Nash, E. R.: A new formulation of equivalent effective stratospheric chlorine (EESC), Atmos. Chem. Phys., 7, 4537-4552, 2007, http://www.atmos-chem-phys.net/7/4537/2007/.

Oman, L., Waugh, D. W., Pawson, S., Stolarski, R. S., and Newman, P. A.: On the influence of anthropogenic forcings on changes in the stratospheric mean age, J. Geophys. Res., 114, D03105, doi:10.1029/2008JD010378, 2009.

Paur, R. J. and Bass, A. M.: The ultraviolet cross-sections of ozone: II. Results and temperature dependence, in Atmospheric Ozone: Proceedings of the Quadrennial Ozone Symposium held in Halkidiki, Greece, 3-7 September 1984, edited by: Zerefos,
C. S. and Ghazi, A., Reidel, Dordrecht, Holland, 606-610, 1985. Pawson S., Stolarski, R. S., Douglass, A. R., Newman, P. A., Nielsen, J. E., Frith, S. M., and Gupta, M. L.: Goddard Earth Observing System chemistry-climate model simulations of stratospheric ozone-temperature coupling between 1950 and 2005, J. Geophys. Res., 113, D12103, doi:10.1029/2007JD009511, 2008.

Plumb, R. A. and Mahlman, J. D.: The zonally averaged transport characteristics of the GFDL general circulation/transport model, J. Atmos. Sci., 44(2), 298-327, doi:10.1175/15200469(1987)044<0298:TZATCO > 2.0.CO;2, 1987.

Prather, M., Midgley, P., Rowland, F. S., and Stolarski, R.: The ozone layer: The road not taken, Nature, 381, 551-554, doi:10.1038/381551a0, 1996.

Ramanathan, V., Cicerone, R. J., Singh, H. B., and Kiehl, J. T.: Trace gas trends and their potential role in climate change, J. Geophys. Res., 90(D3), 5547-5566, doi:10.1029/JD090iD03p05547, 1985.

Rayner, N. A., Parker, D. E., Horton, E. B., Folland, C. K., Alexander, L. V., Rowell, D. P., Kent, E. C., and Kaplan, A.: Global analyses of sea surface temperature, sea ice, and night marine air temperature since the late nineteenth century, J. Geophys. Res., 108(D14), 4407, doi:10.1029.2002JD002670, 2003.

Rosenfield, J. E., Douglass, A. R., and Considine, D. B.: The impact of increasing carbon dioxide on ozone recovery, J. Geophys. Res., 107(D6), 4049, doi:10.1029/2001JD000824, 2002.

Sander, S. P., Friedl, R. R., Ravishankara, A. R., Golden, D. M., Kolb, C. E., Kurylo, M. J., Huie, R. E., Orkin, V. L., Molina, M. J., Moortgat, G. K., and Finlayson-Pitts, B. J.: Chemical kinetics and photochemical data for use in atmospheric studies, Evaluation 14, JPL Pub. 02-25, Pasadena, 2003.

Sarma, K. M. and Bankobeza, G. M. (Eds.): The Montreal protocol on substances that deplete the ozone layer, United Nations Environment Programme, Nairobi, Kenya, 2000.

Setlow, R. B.: The wavelengths in sunlight effective in producing skin cancer: A theoretical analysis, Proc. Natl. Acad. Sci. USA, 71(9), 3363-3366, 1974.

Slaper, H., Velders, G. J. M., Daniel, J. S., de Gruijl, F. R., and van der Leun, J. C.: Estimates of ozone depletion and skin cancer incidence to examine the Vienna Convention achievements, Nature, 384, 256-258, doi:10.1038/384256a0, 1996.

Solomon S., Portmann, R. W., Sasaki, T., Hofmann, D. J., and Thompson, D. W. J.: Four decades of ozonesonde measurements over Antarctica, J. Geophys. Res., 110, D21311, doi:10.1029/2005JD005917, 2005.

Stolarski, R. S., Douglass, A. R., Gupta, M., Newman, P. A., Pawson, S., Schoeberl, M. R., and Nielsen, J. E.: An ozone increase in the Antarctic summer stratosphere: A dynamical response to the ozone hole, Geophys. Res. Lett., 33, L21805, doi:10.1029/2006GL026820, 2006.

Tripathi, O. P., Godin-Beekmann, S., Lefèvre, F., Pazmiño, A., Hauchecorne, A., Chipperfield, M., Feng, W., Millard, G., Rex, M., Streibel, M., and von der Gathen, P.: Comparison of polar ozone loss rates simulated by one-dimensional and three-dimensional models with Match observations in recent Antarctic and Arctic winters, J. Geophys. Res., 112, D12307, doi:10.1029/2006JD008370, 2007.

Velders, G. J. M., Andersen, S. O., Daniel, J. S., Fahey, D. W., and McFarland, M.: The importance of the Montreal Protocol in protecting climate, Proc. Natl. Acad. Sci. USA, 104(12), 4814- 
4819, 10.1073/pnas.0610328104, 2007.

World Meteorological Organization (WMO): Atmospheric Ozone 1985, Global Ozone Research and Monitoring Project, Report No. 16, Geneva, Switzerland, 1985.

Yudin, V. A., Smyshlyaev, S. P., Geller, M. A., and Dvortsov, V. L.: Transport diagnostics of GCMs and implications for 2D chemistry-transport model of troposphere and stratosphere, J. Atmos. Sci., 57(5), 673-699, doi:10.1175/15200469(2000)057<0673:TDOGAI>2.0.CO;2, 2000. 